\title{
¡TODAS SOMOS COMPAÑERAS! LA SORORIDAD COMO FORMA DE EMPODERAMIENTO DE LAS MAESTRAS OAXAQUEÑAS AL INTERIOR DE LA CNTE.
}

Una perspectiva autoetnográfica

\author{
Guadalupe Lizeth Pérez Saucedo
}

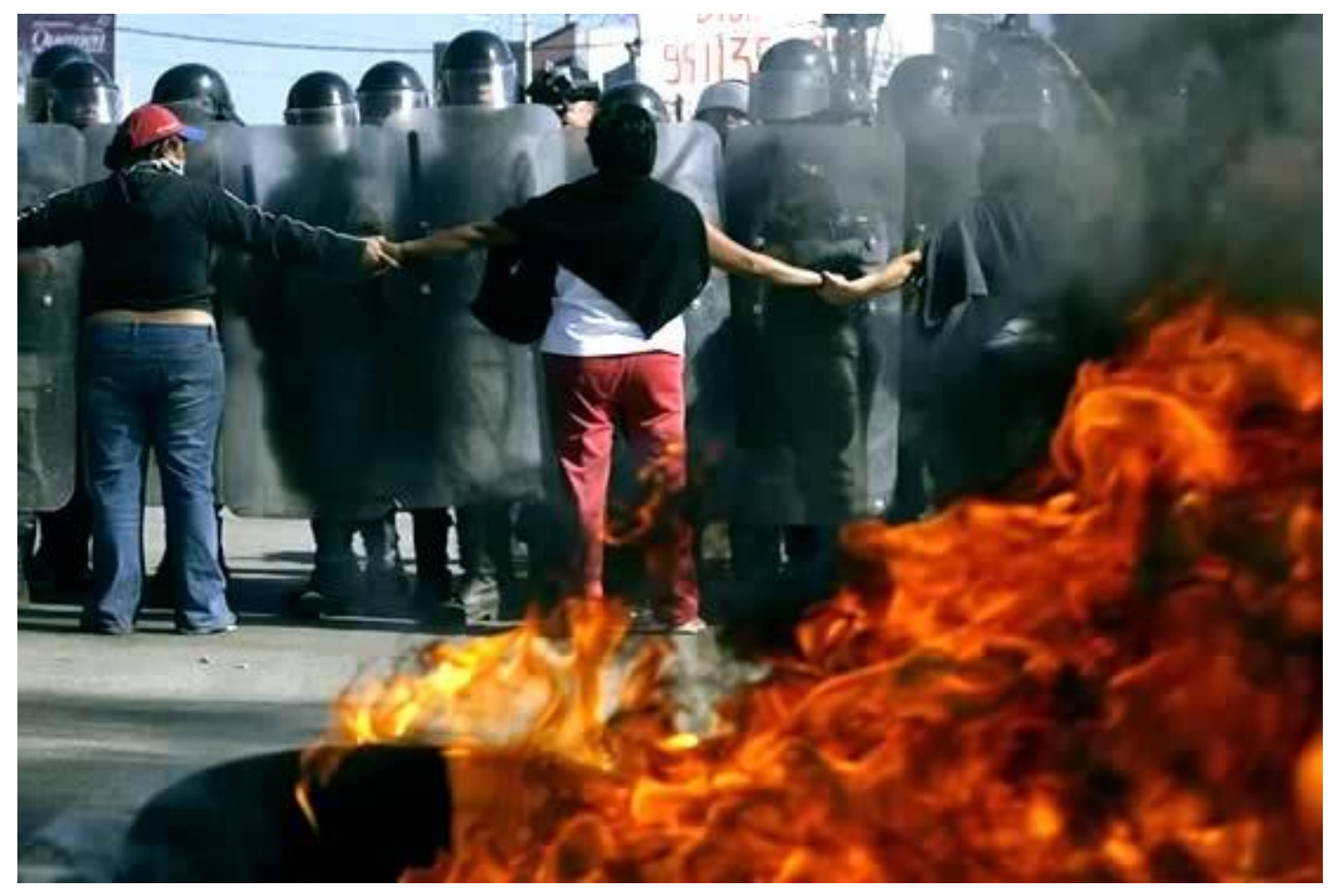




\title{
Gemma
}

\section{¡TODAS SOMOS COMPAÑERAS! LA SORORIDAD COMO FORMA DE EMPODERAMIENTO DE LAS MAESTRAS OAXAQUEÑAS AL INTERIOR DE LA CNTE.}

\author{
Una perspectiva autoetnográfica
}

Guadalupe Lizeth Pérez Saucedo

Supervisor

Amalia Morales Villena

Universidad de Granada

\author{
Co-supervisor \\ Rachel Alsop \\ University of York
}

Julio 2019

Fuente foto de portada: Desalojo del corazón de la resistencia magisterial, autor Carlos Ogaz, Cd. México, 2013.

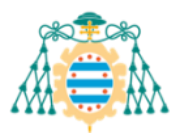




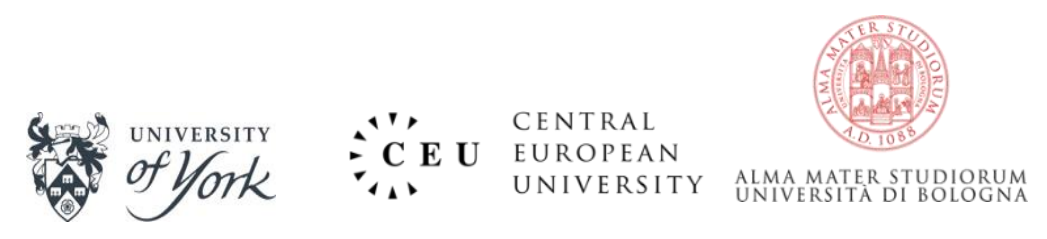




\section{Abstract}

The union struggle has been, and still is, a key element to understand Mexico's history. These organizations have taken a systematical fight since the year 1943, which has not met a truce, in order to improve the workers' conditions. The present research is developed within this context with the objective to identify, from a feminist perspective, the sisterhood relationships that are woven by the militant women from the section XXII of the Coordinadora Nacional de Trabajadores de la Educación en Oaxaca, as part of the labor union (CNTE).

I turn to the feminist ethnography (Acevedo 2007; Blanco 2012) as a method for writing and transmitting the fighting stories to which I had access through my female partners, as well as my own since I have been part of the labor union. Also, I have participated directly with the teacher's protest organized by CNTE in the Mexican capital in September, 2013. My methodology is sustained by the one proposed by Teresa del Valle (2017) to access the past from an autobiographic reflection. I build, in this way, a series of stories in which I compile my evocations as historical references to the popular teachers' movement from the year 2006. Through them, I have identified, following Marcela Lagarde's (2012) characterization, the ethic, political and practical levels in which the sisterhood relationships are produced as strategies of care, resistance and empowerment among the union activist teachers. The vertebrae of this analysis are composed by the key constructs such as "sorority" (Lagarde, 1997 \& 2012), "ethics of care" (Comins, 2007, Lagarde, 2012) and "empowerment" (Azcuy and Palacio, 2008, Magdalena León, 2001). Finally, I suggest that the sisterhood relationships become a way of empowerment for the teacher of the CNTE, since these relationships find the possibility of obtaining power, signaling oppression, reporting abuses and signaling precedent of political participation for future generations.

Key words: autoethnography, labor union, sorority, Oaxaca, care ethics, empowerment, CNTE, SNTE. 


\section{Resumen}

La lucha sindical ha sido y continúa siendo un elemento clave para comprender la historia de México. Estas organizaciones han llevado una lucha sistemática desde el año 1943, que no ha conocido tregua, a fin de mejorar las condiciones laborales de lxs trabajadorxs. La presente investigación se enmarca en este contexto con el objetivo de identificar, desde una perspectiva feminista, las relaciones de sororidad que se tejen entre las mujeres militantes de la sección XXII de la Coordinadora Nacional de Trabajadores de la Educación en Oaxaca, que forma parte del Sindicato (CNTE).

Acudo a la autoetnografía feminista (Acevedo 2007; Blanco 2012) como método de escritura y de transmisión de las historias de lucha a las que tuve acceso por medio de las compañeras, así como a las mías propias al haber sido parte del propio sindicato y haber participado de manera directa en el plantón magisterial organizado por la CNTE en la capital mexicana en septiembre de 2013. Mi metodología se sustenta así, en la que propone Teresa del Valle (2017) para acceder al pasado desde la reflexión autobiográfica. Construyo, de este modo, una serie de relatos que recogen tanto mis evocaciones como referencias históricas al movimiento popular-magisterial del año 2006. A través de ellos, he buscado identificar, siguiendo la caracterización de Marcela Lagarde (2012), los niveles éticos, políticos y prácticos en que se producen dichas relaciones de sororidad como estrategias de cuidado, resistencia y empoderamiento entre las maestras activistas sindicales. Las vértebras de este análisis están compuestas por conceptos claves como "sororidad" (Lagarde, 1997 y 2012), "ética de los cuidados" (Comins, 2007, Lagarde, 2012) y "empoderamiento" (Azcuy y Palacio, 2008, Magdalena León, 2001). Sugiero finalmente que las relaciones sororales se convierten así en una forma de empoderamiento para las maestras de la CNTE, ya que en dichas relaciones se encuentra la posibilidad de obtener el poder, señalar opresiones, denunciar abusos y marcar precedentes de participación política para futuras generaciones.

Palabras clave: autoetnografía, sindicato, sororidad, Oaxaca, ética de cuidado, empoderamiento, CNTE, SNTE. 
A mi madre

Por su fortaleza

A mi padre

Por acompañarme

A las mujeres que me sostienen

Por tanto amor

A mí

Por la valentía 


\section{Agradecimientos}

La vida granadina me pintaba genial, de repente apareció el cáncer y me sentí perdida. Pero ahí estaban ellas, me dedicaron tiempo, llamadas, mensajes, me sostuvieron. Gracias a todas:

A mi madre por ser un ejemplo de entereza, si la vida me da la mitad de tu valentía tengo el éxito asegurado.

A mis hermanas: Ariadna, Fabiola y Dulce porque aprendimos a acompañarnos.

A mis sobrinxs: Elisa, Estefanía, Emilia, Elián porque saben abrazar cuando se tiene el corazón roto.

A mi maestra de la vida: Karina, por guiarme en los momentos de oscuridad.

A mi pareja ideal: Laura \& Loli por alimentarme en todos los sentidos. Por tanto amor.

A mi teórica favorita: Paola por compartir tu sabiduría. Por tu amistad.

A my best teacher: Auxi porque eres un ejemplo de constancia. Por la paciencia.

A mi tutora: Amalia Morales Villena por darme la confianza que necesitaba para terminar. A mis aliadas: Laura, Marta, Paula por la sororidad.

A mis GEMMA'S: Por los momentos vividos.

A las que están del otro lado del mar: Thelma, Betty, Mareli por mostrarme como volver.

A las maestras oaxaqueñas: por inspirarme a luchar

Al profesorado del GEMMA por enseñarme a conciliar la teoría con la práctica.

A mi padre: Eucario Arturo por no dejarme rendir. Por existir.

A mi hermano: Arturo Antonio por siempre estar.

¡A la vida, siempre gracias a la vida!

Segura estoy que habrá tiempos mejores 


\section{Vulnerabilidad y resistencia}

Salir, gritar, resistir

Salir, gritar, resistir

Temer, temer, temer, temer

Pero seguimos resistiendo,

El miedo no nos paraliza

los gritos se siguen oyendo

¡Demandamos el derecho a existir!

Cada dos de noviembre, las puertas de Mictlán se abren

lxs ausentes se levantan a visitarnos,

vuelven y se sorprenden,

se sorprenden porque nos encuentran

cada vez más quietxs, como si los reinos

estuvieran invertidos y aquí vivieran lxs muertxs.

Ahora nos toca levantarnos a lxs vivxs

Guadalupe Lizeth Pérez Saucedo

York, 2018 


\section{Índice}

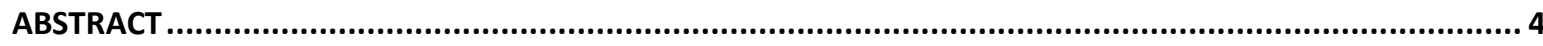

RESUMEN

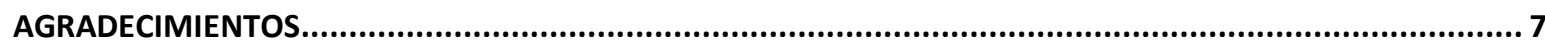

ÍNDICE

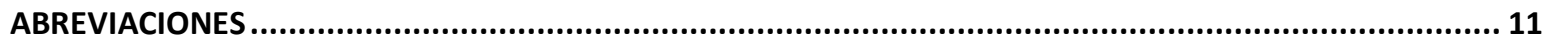

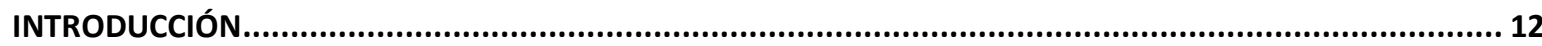

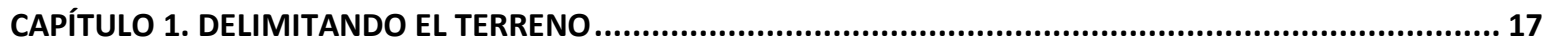

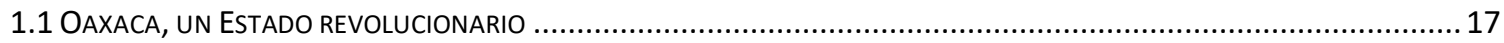

1.2 ConteXto histórico de LA Sección XXII: Del Sindicato NaCiOnal de Trabajadores de la Educación a LA

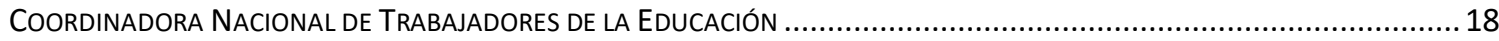

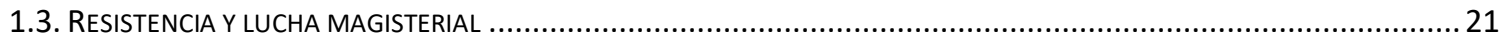

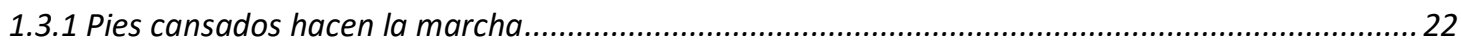

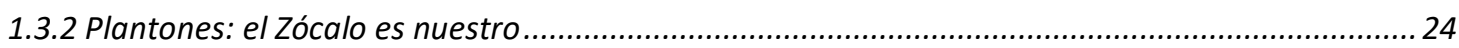

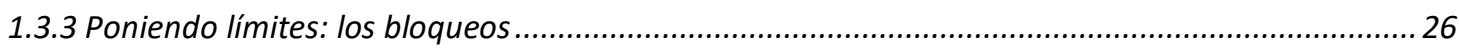

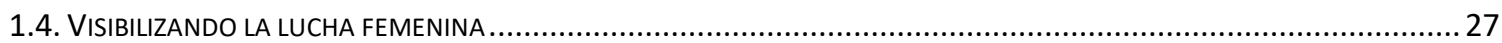

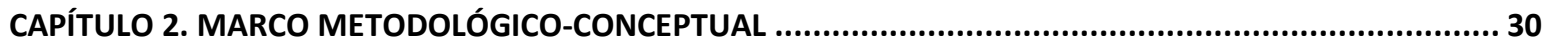

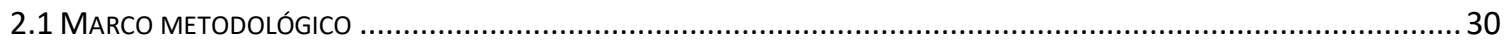

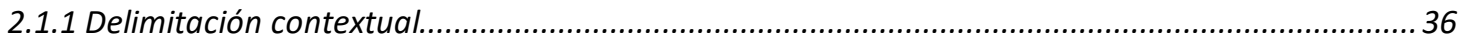

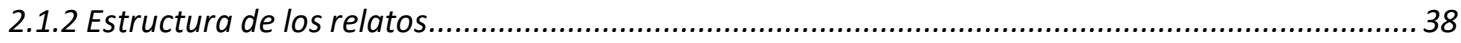

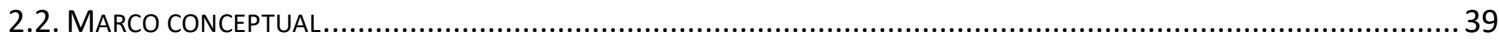

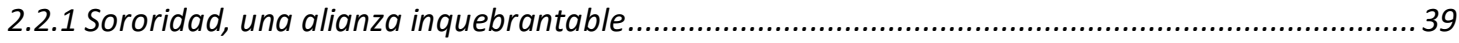

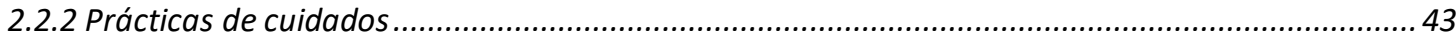

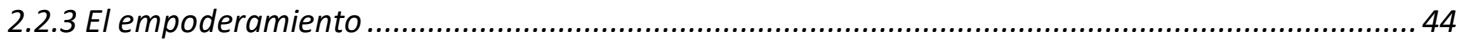

CAPÍTULO 3 LOS RELATOS: iTODAS SOMOS COMPAÑERAS! LAS RELACIONES SORORALES EN LA COORDINADORA NACIONAL DE TRABAJADORES DE LA EDUCACIÓN................................................... 46

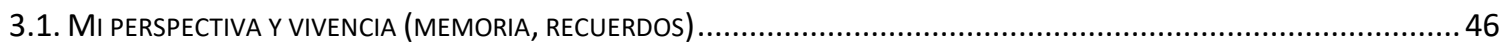

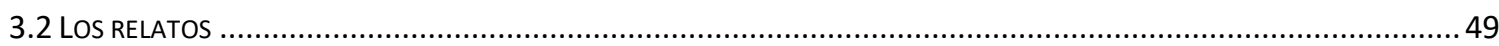

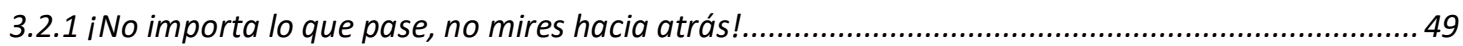

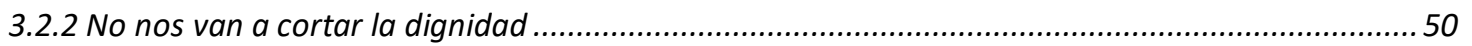

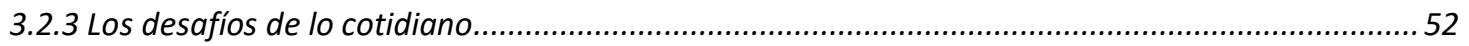




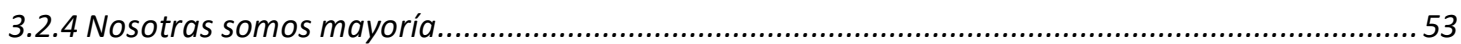

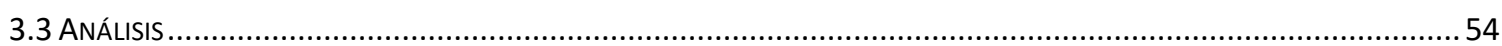

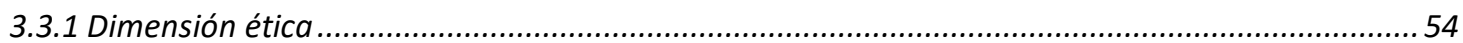

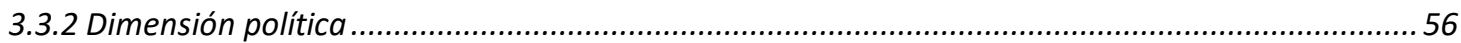

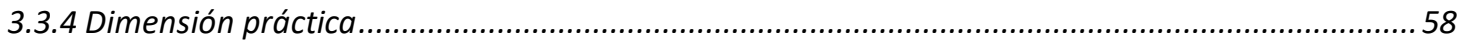

CONCLUSIONES, TEJIENDO REDES DE EMPODERAMIENTO EN LA SECCIÓN XXII DE LA CNTE................... 59

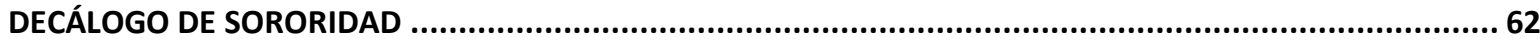

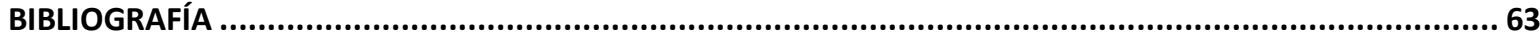




\section{Abreviaciones}

CNTE

SNTE

APPO

COMO

Sección XXII
Coordinadora Nacional de Trabajadores de la Educación

Sindicato Nacional de Trabajadores de la Educación

Asamblea Popular de los Pueblos de Oaxaca

Comunidad de Mujeres Oaxaqueñas

Nombre de adherencia del Estado de Oaxaca a la SNTE/ CNTE 


\section{INTRODUCCIÓN}

La noche comienza a caer, después de un largo día de actividades y bloqueos han dado la instrucción de volver iEs todo por hoy, volvamos en operación hormiga al campamento! Con el cansancio consumiendo mi cuerpo y pensamiento vuelvo a pie a la plancha del gran zócalo capitalino. Entre las carpas y tiendas de campaña se encuentra el lugar donde podré descansar. Descansar es una ilusión después de un día tan extenuante, pero sólo es eso, una ilusión.

Como todas las noches, la amenaza de desalojo está presente, los avances en la mesa de negociación del Sindicato y el Gobierno Federal son escasos. La presencia de la policía es cada vez más notoria, los helicópteros sobrevuelan la zona tres veces al día, las rondas de vigilancia aumentan. A mi lado duermen tres maestras que han sido mis compañeras durante varios días, nos repetimos las mismas recomendaciones: no te duermas profundamente, duerme con los zapatos puestos, esconde todo lo que los relacione con el sindicato, en caso de desalojo corre en dirección al monumento de la Revolución ahí nos encontramos. Entre angustia, miedo e incertidumbre comienza otra noche, una noche que no acaba...

(Guadalupe Pérez, 2019) 
En México, el 61 por ciento del magisterio nacional está conformado por mujeres, y en la lucha de la Coordinadora Nacional de Trabajadores de la Educación (CNTE) contra la reforma educativa ellas constituyen la fuerza motriz que organiza, propone, decide, moviliza los cuadros intermedios y encabeza la resistencia; sin embargo, pocas investigaciones se han hecho sobre su participación. Como maestra y militante de CNTE he decidido visibilizar el papel de las mujeres al interior del Sindicato desde la experiencia vivida, es decir, desde el activismo.

La investigación activista (de los movimientos sociales) puede ser uno de los instrumentos de transformación crítica de la realidad, capaz de generar conocimientos desde la subjetividad más allá de las jerarquías y limitaciones académicas, y capaz también de crear espacios y mecanismos de producción, intercambio y reflexión colectiva a la vez que sirve para denunciar la mercantilización y privatización de los conocimientos actuales (Collectiu investigacció, 2005, p.22).

Durante mucho tiempo he evitado hablar de mi experiencia activista al interior de la Coordinadora Nacional de Trabajadores de la Educación porque he minimizado la importancia de mi participación y de las miles de maestras que conforman la CNTE. Sin embargo, he advertido que no he sido la única en hacerlo, pues, a pesar de que hemos sido determinantes para sostener el movimiento magisterial, resulta imposible encontrar información del tema. Como siempre ocurre, y ya lo advirtió Abigail Brooks en su texto "Feminist standpoint epistemology" (Brooks y Hesse-Biber 2007), nuestra participación ha sido invisibilizada, incluso por nosotras, las protagonistas

Después del encuentro con el libro "Historia de una maestra" de Josefina Aldecoa (2005) reconocí la importancia de contar lo que como maestra he vivido, ahora me resulta apremiante escribir al respecto, y al estilo de la autora contar mi historia para visibilizarla: soy Guadalupe Lizeth, maestra rural y activista desde 2009. Me posiciono en una genealogía de mujeres indígenas de la Sierra Sur del Estado de Oaxaca, México, reconociéndome en una situación de privilegio por tener la oportunidad de estudiar un Máster en Europa, (hecho que agradezco profundamente al GEMMA) que además del financiamiento económico, me ha dado los aprendizajes y las herramientas para reconciliar práctica y teoría las cuales me han permitido construir esta Tesis de Fin de Master. Motivada por la necesidad de contar mis experiencias y las de otras mujeres. De esta necesidad surge esta investigación que tiene 
como propósito, dar cuenta, a través de mi experiencia, de las relaciones de sororidad que se tejen entre las mujeres militantes de la sección XXII de la Coordinadora Nacional de Trabajadores de la Educación.

Desde el momento de postularme como becaria del máster GEMMA Erasmus Mundus tenía en mente elaborar una propuesta educativa que promoviera una educación igualitaria en las aulas de la Sierra Norte, donde me había desempeñado durante más de diez años como profesora. Mantuve esta idea hasta muy avanzado el máster; pero en el fondo había algo en la propuesta que no terminaba de convencerme, las ideas no fluían y decidí cambiar de tema. Tomé la determinación de escribir sobre mí, y mi experiencia como activista de la que escasas veces había hablado porque no la consideraba importante. Me parecía una actividad común participar en protestas, marchas, plantones, escapar de la policía, en conclusión, había naturalizado la violencia. Fue después de una conversación con mi amiga Laura que pude ver lo extraordinario de los eventos, empecé a escribir recuerdos sueltos, relatos, descubrí que tenía mucho para contar. Recordar no fue una tarea fácil, porque algunos episodios eran dolorosos, angustiantes. Al final, la escritura fue un proceso catártico y estoy orgullosa del resultado.

De manera histórica, los sindicatos, a través de sus luchas, han servido para mejorar las condiciones laborales de los trabajadores, cumpliendo así su objetivo principal. Sin embargo, en ocasiones ha ocurrido que este movimiento se vuelve en contra de sus principios haciendo imperativo revirar las participaciones, replantear estrategias y crear nuevos organismos. Fruto de la Revolución Industrial y del sistema económico capitalista, la organización sindical hace eco de las problemáticas que enfrentan la clase obrera, su actuar va más allá de articular la lucha contra la clase patronal y el Estado (Toledano 2003). Por lo que corresponde al sistema educativo mexicano, fue a partir de 1930 cuando comenzó a inquietar e incomodar a los maestros, la inestabilidad de su trabajo, los muy reducidos sueldos y la persecución de que eran objeto. Así pues, los antecedentes de la lucha sindical de los profesores en México se ubican históricamente en 1890, durante el mandato del presidente Porfirio Díaz. Las grandes agrupaciones de maestros, hasta antes de 1934, se originaron en huelgas magisteriales de mayo de 1919 y la huelga de Veracruz en 1927 y 1928 
(Navarro 2016). Ambos movimientos incidieron en la construcción y fortalecimiento de la Confederación Mexicana de Maestros.

En este contexto de lucha se creó en el año 1943, el Sindicato Nacional de Trabajadores de la Educación (SNTE, de ahora en adelante) para el fortalecimiento de la defensa de los derechos laborales, sociales, económicos y profesionales de los miembros del Sistema Educativo Nacional Mexicano, dependientes de la Secretaría de Educación Pública. Las inconformidades ante el corporativismo, el autoritarismo gubernamental y los nexos entre el Estado y el SNTE, dieron pie a la creación (dentro mismo del sindicato) de la Coordinadora Nacional de Trabajadores de la Educación (en adelante CNTE o Coordinadora) con la intención de tener un grupo de resistencia que no cediera de manera servil a las coacciones del Estado. La Coordinadora se define a sí misma como una fuerza democrática e independiente que lucha dentro del SNTE, su objetivo es recuperar la organización gremial como vía para la defensa de los derechos laborales (Navarro 2016). En el Estado de Oaxaca, la subdivisión de la CNTE al interior del SNTE busca modificar las estrategias de acción y formas de protesta del magisterio oaxaqueño contra el Estado Mexicano, con el fin de obtener respuesta a las demandas de educación, justicia y seguridad social.

Es en este escenario sindical que sitúo el presente trabajo autoetnográfico. El objetivo principal de esta investigación es identificar, desde una perspectiva feminista, los niveles éticos, políticos y prácticos en que se producen dichas relaciones de sororidad como estrategias de cuidado, resistencia y empoderamiento entre las maestras activistas sindicales. Para ello, me amparo en la investigación autoetnográfica, en el marco de la epistemología y la investigación feminista, utilizando el concepto de "sororidad" como figura estratégica relacional en los niveles éticos, políticos y prácticos que nos permite hacer comunidad (Aguirre \& Hernández, 2016).

Como sostiene la filósofa feminista Sandra Harding (1987), cada quien lucha desde sus propias trincheras, entendiendo estas luchas como posiciones/puntos de vista éticas y políticas particulares. Este Trabajo Final de Máster es mi grano de arena para contribuir en reconocer y visibilizar estrategias de cuidado y resistencia. En este sentido, siguiendo la importancia que implica identificar mis políticas de ubicación (Rich 1987), me constituyo como informante directa, al haber sido parte del propio sindicato y haber participado de 
manera directa en el plantón magisterial organizado por la CNTE en la capital mexicana en septiembre de 2013 y, a través de evocaciones y por referencia histórica al movimiento popular-magisterial de 2006 .

La estructura de esta investigación estará organizada en cuatro partes principales. En primer lugar, ofreceré un breve panorama de la organización sindical en México, en referencia a la composición del sector educativo, de manera específica a las particularidades sociopolíticas y la relevancia que cobra a nivel nacional el Estado de Oaxaca. En segundo lugar, analizaré la perspectiva conceptual y metodológica que servirá de marco analítico a las experiencias de cuidados y empoderamiento que se despliegan por las mujeres en los movimientos magisteriales. En el tercer capítulo expondré, a modo de relatos y valiéndome del método autoetnográfico, las estrategias y las relaciones de sororidad que desde la corporeidad viví y compartí con mis compañeras de lucha y profesión. Finalmente, expondré las conclusiones a las que llegué después de analizar y establecer un diálogo entre la teoría feminista y el activismo, el cual finalmente se traduce en una vertiente feminista dentro de un espacio masculinizado como es la Sección XXII de la Coordinadora Nacional de Trabajadores de la Educación. 


\section{Capítulo 1. Delimitando el terreno}

\subsection{Oaxaca, un Estado revolucionario}

En el sur de México, Oaxaca ofrece una impresión de pasados indígenas y coloniales entreverados que gravitan sobre un presente sin aliento. Un mundo indígena que persiste entre pobreza, fiestas comunitarias, emigración y localismo, conflictos intercomunitarios y una calma somnolienta que tan súbitamente se quiebra (en momentos de ira colectiva) como se restablece sin alterar condiciones previas de existencia (Pipitone 2011, 33).

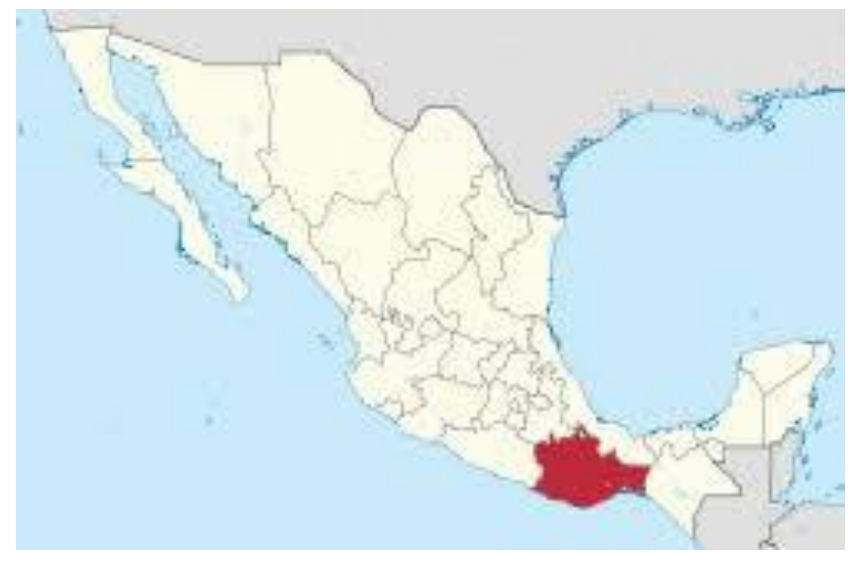

Estado de Oaxaca, México. Fuente: Fuente: Oaxaca Mío ${ }^{l}$

Oaxaca es el quinto estado más grande a nivel nacional con una extensión territorial de 95.364 kilómetros cuadrados, el 90\% del suelo es accidentado pues confluyen en él los conjuntos montañosos de la Sierra Madre del Sur, la Sierra Madre de Oaxaca, la Sierra Madre de Chiapas y la Sierra Atravesada. Esto ocasiona que la dispersión poblacional sea alta y se localicen en el estado más de diez mil poblaciones. De acuerdo con datos del XII Censo General de Población y Vivienda de 2015, la población total de la entidad oaxaqueña es de 3.967.889 habitantes, de los cuales $47.8 \%$ son hombres y 52.2\% son mujeres (INEGI 2015).

Oaxaca se ha caracterizado por gran cantidad de conflictos históricos, políticos y sociales que han desembocado en las divisiones que hoy presenta el Estado. Son estas

\footnotetext{
${ }^{11}$ https://www.oaxacamio.com/imagenesoaxaca/icos_comollegar/ico_ruta_mex_pue_oax_pto.jpg
} 
divisiones y la situación de pobreza y marginación existente en la entidad lo que ha orillado a que grandes masas de población emigren hacia otros estados de la república, especialmente hacia los Estados Unidos.

Oaxaca es también, uno de los Estados con más alto nivel de marginación social y económica, seguido por Guerrero y Chiapas. De los 570 municipios existentes en la entidad, un 60 por ciento depende del trabajo artesanal y agrícola; esta última actividad con el carácter de subsistencia y autoconsumo. Aunado a lo anterior en el estado existen los más altos índices de analfabetismo, desnutrición, así como poblaciones carentes de servicios básicos. En el contexto político, es uno de los estados con más altos niveles de oposición al partido dominante, que se refleja en continuas manifestaciones y protestas.

\subsection{Contexto histórico de la Sección XXII: del Sindicato Nacional de Trabajadores de la Educación a la Coordinadora Nacional de Trabajadores de la Educación}

Con el objetivo de contextualizar el movimiento sindical oaxaqueño, hago una breve construcción histórica que ubicará en el tiempo al sindicalismo mexicano del sector educativo, así como el nacimiento de la Sección XXII en Oaxaca correspondiente al espacio militante del que formo parte. En la historia de México, los sindicatos han sido creados para asegurar los derechos y condiciones laborales de los y las trabajadoras. Lombardo Toledano (2003) afirma que el sindicato de trabajadores es uno de los frutos de la Revolución Industrial y del sistema económico capitalista; con su labor hace eco de las problemáticas que enfrenta la clase obrera. No obstante, reconoce que su actuar va más allá de organizar la lucha contra la clase patronal y el Estado. A partir de esta afirmación el autor define al sindicato como: "Organizaciones de masas de los trabajadores como organismos de frente único, independientemente de sus opiniones políticas o de sus creencias, para defender los intereses y derechos de su clase y elevar constantemente su nivel de vida (Toledano 2003, 45).

Así pues, para el fortalecimiento de la defensa de los derechos laborales, sociales, económicos y profesionales de los miembros del Sistema Educativo Nacional Mexicano se crea en 1943 el Sindicato Nacional de Trabajadores de la Educación que está integrado por "los trabajadores de base, permanentes, interinos y transitorios al servicio de la educación, dependientes de la Secretaría de Educación Pública [...], quienes son parte de manera 
obligatoria, así como los jubilados y pensionados del servicio educativo de las entidades citadas (Bensusán 2011, 21).

En la misma línea, a los trabajadores del Estado de Oaxaca, les tocó constituirse el 3 de noviembre de ese mismo año, dando origen a la Sección XXII del SNTE. La constitución de la sección XXII fue un logro en la lucha de los derechos laborales; sin embargo, el sindicalismo en México tiene una gran carga histórica de fomento del acarreo ${ }^{2}$ y la apatía entre sus agremiados, obedeciendo a una larga tradición que se conoce como "charrismo sindical”. En palabras de Samuel León, el charrismo sindical, un concepto que surgió en México durante el año 1948, es una de las formas del corporativismo político que ha servido como sistema de control para sostener y reproducir regímenes políticos autoritarios y corruptos. El corporativismo en México ha servido, además, para apuntalar la relación entre patrones, gobierno y sindicatos, donde la acumulación de la riqueza y la distribución del poder se llevan a cabo a costa del empobrecimiento de los trabajadores (S. León 2005).

De esta manera, el rasgo político esencial del charrismo es la conjunción del corporativismo y el autoritarismo gubernamental; los nexos y la cercanía establecida entre el Estado y el SNTE genera inconformidad en los estados de Guerrero, Chiapas, Michoacán y Oaxaca quienes acusan a la dirigencia nacional de traición, al dejarse captar por el Gobierno en lugar de responder a los intereses de los trabajadores. Dicha inconformidad llevó a la creación, al interior del mismo SNTE, de la Coordinadora Nacional de Trabajadores de la Educación, con la intención de tener un grupo alterno dentro de este movimiento, que no ceda a las coacciones del Estado. De esta forma, la Coordinadora se define a sí misma como una fuerza democrática e independiente que lucha dentro del SNTE, su objetivo es recuperar la organización gremial como vía para la defensa de sus derechos laborales (Bensusán 2011). La subdivisión de la CNTE al interior del SNTE busca modificar las estrategias de acción y formas de protesta del magisterio oaxaqueño contra el Estado Mexicano para obtener respuesta a las demandas de educación, justicia y seguridad social.

Desde sus inicios la CNTE tuvo fuertes nexos con la izquierda política mexicana, sin estar afiliada a ningún partido. Su base ideológica es la democracia como forma de

\footnotetext{
${ }^{2}$ Este término en México se utiliza para nombrar la acción de aumentar la cantidad de personas en eventos o nóminas, con el fin de justificar el uso de recursos o simular adeptos.
} 
organización gremial. Si bien es cierto que la Coordinadora está conformada por cuatro Estados, es el magisterio de Oaxaca quien impulsa y encabeza las protestas. Al respecto Fuentes Molinar escribe:

Con la claridad que sólo da la acción concreta, y al margen de toda ideologización, los maestros oaxaqueños han entendido que la movilización efectiva en favor de demandas laborales es inseparable de la democratización y la autenticidad representativa del sindicato [...] saben que, así como un sindicato unificado ha sido la forma más eficiente del control, también es la vía más práctica de la acción colectiva (2007, pág. 28).

Las manifestaciones y actos de protesta magisteriales en Oaxaca lo han convertido en un estado estandarte de la lucha y resistencia permanente. En Oaxaca, se vive un contexto socio político particular; junto con Chiapas y Guerrero está considerado uno de los estados más pobres del país. De acuerdo con datos del Consejo Nacional de Evaluación de la Política de Desarrollo Social, el 38.1\% de la población del estado se encuentra en pobreza alimentaria, el $46.9 \%$ en pobreza de capacidades y el 68\% en pobreza de patrimonio (CONEVAL 2019). La pobreza alcanza a poco más de las dos terceras partes de la población del estado, en sus diferentes intensidades. Esta misma situación ha generado una alta desigualdad social, que ha derivado en la combatividad y radicalización de la sociedad oaxaqueña que en múltiples ocasiones ha mostrado su fortaleza popular. Históricamente Oaxaca ha sido el único estado de la República Mexicana que ha logrado destituir a dos gobernadores: Edmundo Sánchez Cano en 1947 y Manuel Mayoral Heredia en 1952 (S. León 2005). La constante en estos gobiernos era impulsar reformas a la ley que atentaban contra los intereses de las y los trabajadores, maestros y estudiantes. Los conflictos llevaron al estado a tales crisis políticas que los gobernadores no tuvieron otra opción que dejar el gobierno. Ni el Partido Revolucionario Institucional (PRI), que gobernaba el país y la entidad, fue capaz de controlar las manifestaciones sociales en la capital oaxaqueña (Martínez 2009).

Al interior de estas protestas, lxs maestrxs han jugado un papel fundamental en la configuración y transformación de la entidad. El ejemplo más ilustrativo de ello es el movimiento magisterial popular del 2006, un conflicto social que enfrentó al pueblo oaxaqueño con el gobierno del estado (Barraza 2010). Esta confrontación se componía, por un lado, del gobierno -tanto estatal como Federal-, la clase empresarial y los cuerpos policíacos locales y Federales; por el otro, de la Coordinadora Nacional de Trabajadores de 
la Educación y la Asamblea Popular de los Pueblos Oaxaqueños. Este conflicto colocó a Oaxaca en el centro de la mirada internacional, siendo reconocida por ser el corazón rebelde de México, la Ciudad de la resistencia.

\subsection{Resistencia y lucha magisterial}

El 26 de septiembre de 2014, la desaparición de 43 estudiantes de la Normal Rural de Ayotzinapa, paralizó México. Existen muchas versiones de este hecho, pero la verdad está lejos de ser descubierta. Como maestra y activista de la Coordinadora, participé en las protestas para clamar justicia. Fuimos miles de personas gritando en las calles, haciendo de la manifestación corporal una forma política de resistencia: vulnerabilidad, resistencia, protesta, mortalidad, cuerpo, miedo. Durante las protestas he sentido miedo, nunca miedo a morir, sino a desaparecer. Imaginar a mis padres buscándome, sufriendo, gritando mi nombre como he escuchado a los padres de los 43, a los hijos de las muertas de Juárez, a mis amigxs, alumnxs y a miles de personas que desaparecen cada día. Sara Ahmed (2014) habla esta sensación de miedo como el temor de un objeto que se nos acerca. Así explica que el miedo, como el dolor, se siente como una forma desagradable de intensidad causada por la anticipación de daño o herida, acelerando el corazón, el cuerpo tenso y que incita a la huida algunas veces, y a la paralización en otras. El miedo es entonces una respuesta razonable a la vulnerabilidad (p. 114). En palabras de Judith Butler (2015) reconocernos a nosotrxs mismos como vulnerables, pero con agencia, es una forma de resistencia, la única que tenemos. Por eso protesto en las calles, porque estoy demandando el derecho a existir.

De manera histórica la calle ha sido uno de los instrumentos más eficaces para reunir y explicitar el malestar social, es en este sitio donde lo público encuentra su mejor sede, pero es sin duda también el lugar preferido para el ensañamiento policial. El llamado orden público constituye el arma más visible para probar la fuerza represiva del Estado. La represión está siempre latente y, lo que en un inicio es el ejercicio del derecho a la libertad de expresión se convierte en una amenaza constante (Eltit 2016). En México protestar en la calle o en los lugares públicos donde la policía está presente conlleva siempre el riesgo de ser detenida, maltratada, e incluso asesinada, la operación de los poderes policiales en contubernio con el gobierno ha hecho de las manifestaciones una actividad de riesgo, pero al mismo tiempo 
ineludible. En el momento en que la gente ya no puede confiar en la ley, la ley ha emancipado a la gente para crear su propio futuro político. Cuando la ley es un régimen violento, uno tiene que manifestarse en contra, a fin de oponerse, paradójicamente, a la violencia. No hay olvido, no hay fin a la demanda de justicia [...] (Butler, en Lugo 2015). Estas demandas de justicias son exigidas por la CNTE a través de marchas, plantones y bloqueos, son las alternativas de lucha y resistencia la demostración de la fuerza gremial.

\subsubsection{Pies cansados hacen la marcha}

Las marchas son una manera de hacer pública la inconformidad, una forma de hacer presión para que los organismos de gobierno acepten la interlocución. Estos desfiles multitudinarios se caracterizan por el bloqueo de las calles principales de la ciudad y el grito de consignas en contra del gobierno, en ellas se denuncian las desigualdades sociales, las inconformidades (Leyva 2010). En el contexto específico del 2013, la exigencia de educación pública, gratuita e inclusiva, así como demandas de seguridad laboral. En la ciudad de México se llevan a cabo las marchas más extensas, en tiempo y distancia. Al ser más de 70.000 agremiados la ubicación y distribución de contingentes está organizado de forma descendente por regiones ${ }^{3}$, sectores, delegaciones y centros de trabajo. Por cuestiones de seguridad y logística durante los recorridos se hace una formación de cuatro hileras, las externas están constituidas por hombres y las internas por mujeres, aunque pocas veces se respeta pues la mayoría nos inclinamos por buscar personas conocidas y/o afines para formar pequeñas zonas seguras.

Por tratarse de la actividad con mayor impacto dentro de las movilizaciones de la CNTE, las marchas se vuelven un objetivo común de agresión policial. Un episodio de esta situación ocurrió durante la marcha convocada por la dirigencia sindical para instalar la mesa de negociación con el gobierno federal, el 8 de septiembre de 2013, un día después de la instalación oficial del plantón en la capital del país, eso implicó una noche durmiendo en el asfalto, salvando las inclemencias del tiempo que para esas fechas se torna de lluvia ligera a torrencial en cuestión de segundo. El primer reto de esa mañana fue encontrar el punto de

\footnotetext{
${ }^{3}$ El Estado de Oaxaca cuenta con ocho: Sierra Norte, Sierra Sur, Cañada, Costa. Istmo, Mixteca, Papaloapan y Valles Centrales
} 
reunión con mi centro de trabajo, dos maestras y yo habíamos ocupado demasiado tiempo en encontrar sanitarios. La ruta trazada fue del Zócalo a la residencia oficial del presidente de la República conocida como "Los Pinos", un total de cinco kilómetros que a primera vista no representan mayor esfuerzo, pero bajo la dinámica de "pies cansados", es decir, caminando tramos cortos y deteniéndonos ratos largos para bloquear las avenidas principales, convertían el recorrido de hora y media en cinco o seis horas, transformándola en una actividad sumamente agotadora.

Así, al ser una marcha de pies cansados, la caminata era lenta y pausada. Todo transcurría con normalidad, nosotrxs gritando consignas, los vendedores ambulantes pregonando sus productos y los altavoces dando indicaciones generales. De repente, todos comenzaron a correr y se escuchaba la instrucción ;Cierren filas compañerxs! ¡Cierren filas! No tardamos en descubrir el origen de la agitación: grupos de choque infiltrados por el gobierno se estaban enfrentando a los granaderos ${ }^{4}$, habían comenzado a quemar llantas y hacer pintas. Nos replegamos a una zona segura y desde ahí emprendimos el regreso. La infiltración de porros ${ }^{5}$ en la marcha había logrado la detención de tres maestros, una maestra, agresiones leves a otros tantos, y el objetivo principal: transformar ante la imagen pública, una marcha pacífica en actos vandálicos.

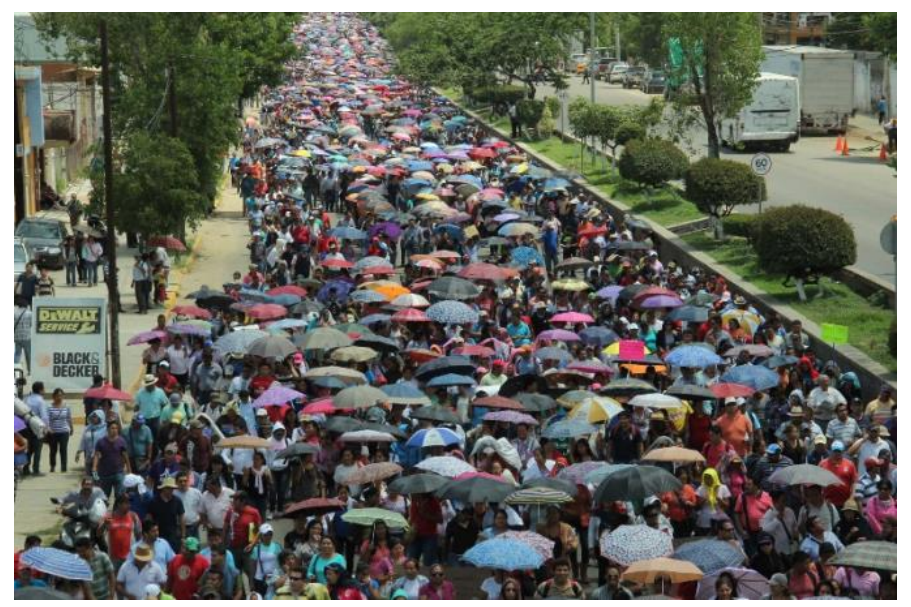

Megamarcha en Oaxaca, 2008. Fuente: Anel Torres ${ }^{6}$

\footnotetext{
${ }^{4}$ Unidades de policías especializadas en tareas antidisturbios, provistos de macanas (porras) y escudos.

5 Grupo de choque financiados por el Estado, se caracterizan por irrumpir en de forma violenta las manifestaciones.

${ }^{6}$ Periódico Noticias Voz e imagen de Oaxaca www.megamarchadelaniversario/educacion/marcha-s-22-en$\underline{\text { oaxaca }}$
} 


\subsubsection{Plantones: el Zócalo es nuestro}

El plantón es otra estrategia de gran impacto, que consiste en la instalación de lonas, carpas y casas de campaña en lugares estratégicos de la ciudad, generalmente en el zócalo ${ }^{7}$ de la Ciudad de México, la Cámara de Diputados, el Monumento a la Revolución. La permanente amenaza de desalojo de estas plazas genera un estado de alerta constante, principalmente en las noches. Martínez Luna describe en su obra "Sindicalismo y represión” (2009) la forma de organización de estos plantones: "los comités de lucha y grupos brigadistas tienden un cordón de seguridad a su alrededor, distribuyen a los contingentes por regiones y delegaciones, idean mecanismos de identificación para los representantes [...] forman cientos de brigadas que informarán y demandarán apoyo político y económico [...]” (p. 234). El plantón se constituye así, en una escuela de lucha; la lucha en un sentido literal de subsistencia, durmiendo y viviendo en condiciones precarias, con dificultad para preparar alimentos, cubrir necesidades básicas de aseo y limpieza aunado a un desgaste económico, físico y moral. También en un sentido de resistencia social, una forma de hacer presencia en el ámbito público para demandar la exigencia de justicia.

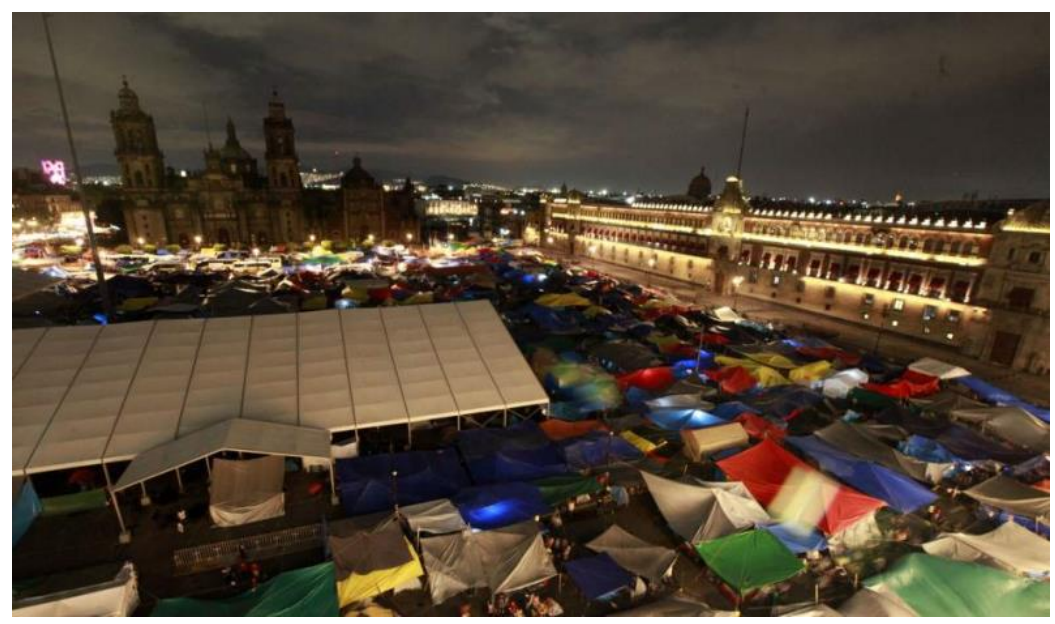

Plantón en la Cd de México, 2013 Fuente: Veinte minutos ${ }^{8}$

\footnotetext{
7"El zócalo se erige como una fuente inagotable de rememoraciones que le confieren a nuestro entrañable rectángulo urbano el justo título de placeta cultural y política del país, el título de corazón palpitante de México" (1994, p. 18).

${ }^{8}$ Autor Juan García www.20minutos.com.mx/noticia/7800/0/maestros-cnte/-planton/zocalo/
} 
El plantón instalado en el zócalo de la ciudad de México en septiembre de 2013 se apostó con clara conciencia del desalojo, lo anterior por la cercanía de la celebración del CCIII aniversario de la independencia de México. La instalación de los campamentos siguió el orden acostumbrado, se establecieron roles de guardia para vigilar las entradas principales y advertir con anticipación situaciones no previstas; como todos los años se improvisaron cocinas, se acordaron salidas de emergencia y se realizaban rondas de asamblea constantes. En aquella ocasión opté por una casa de campaña pequeña consciente que en caso de desalojo tendría que dejarla, había conseguido cartones y plástico para protegerme de la lluvia que en esas fechas es constante y vuelve aún más nostálgico el panorama. A mi lado había compañeras de la delegación que recién había conocido pero que me generaban la suficiente confianza para pedir que vigilaran la entrada de la casa de campaña mientras me cambiaba, compañeras de cenas improvisadas, de charlas superficiales y profundas, de círculos de lectura sobre las modificaciones al artículo tercero, de silencios, de añoranzas (pues la mayoría había dejado a sus hijxs en la Cd. de Oaxaca), de miedo y de zozobra. Compañeras de lucha en toda la extensión de la palabra. Así pues, el plantón se convierte para nosotras en un elemento concientizador y alianzador.

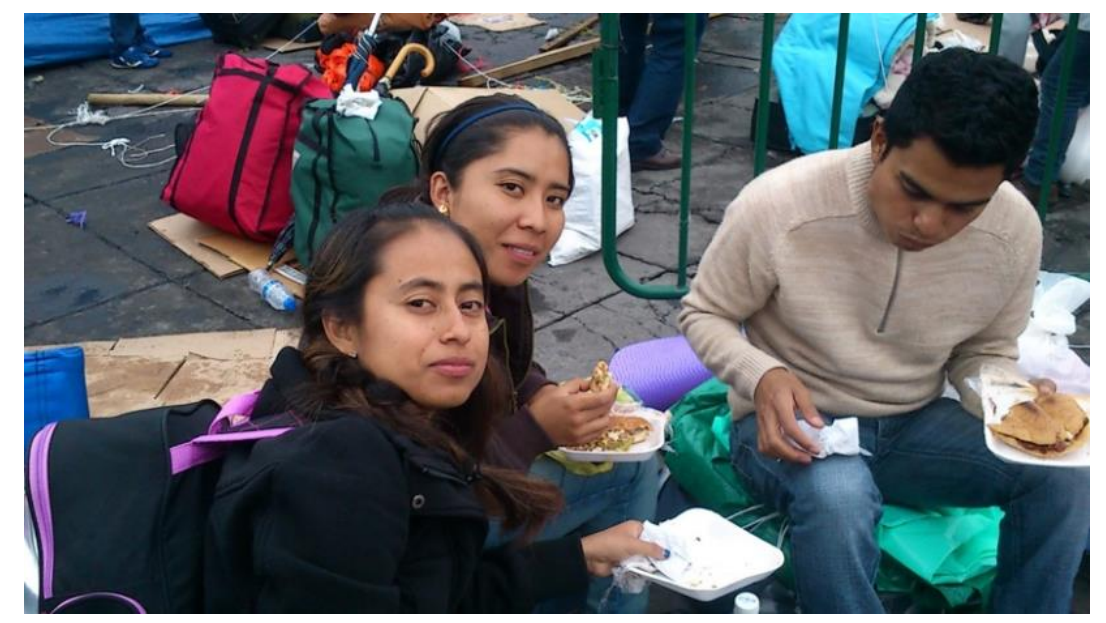

Comiendo en el plantón, septiembre de 2013 Fuente: archivo propio 


\subsubsection{Poniendo límites: los bloqueos}

Los bloqueos carreteros son las actividades más desgastantes, la desesperación de los automovilistas porque les permitamos pasar, tensa el ambiente y en varias ocasiones son causa de choque entre el magisterio y la población. La organización de estos bloqueos está a cargo de los hombres, ellos son los encargados de "negociar" con los choferes de camiones y vehículos de carga, la actividad consiste en impedir el paso de los automóviles por algunas horas tomando el control de los vehículos. El rol de las mujeres en esta actividad es reforzar la valla humana que se forma en la carretera. Al momento de escribir esto me sorprende descubrir la normalidad con la que realizaba esa actividad; recién ahora me hago consciente del peligro al que nos exponíamos. En alguna ocasión, mientras permanecíamos bloqueando la salida México-Toluca, la actividad de bloqueo quedó a cargo de un grupo de mujeres. La tarea consistía en permitir el paso sólo a los automóviles e impedírselo a los camiones, a fin de usarlo para crear una barrera e impedir el paso en general. Éramos un grupo de cinco maestras y nos tomamos con seriedad la actividad, aunque fuimos las únicas en hacerlo: los camioneros no nos escuchaban, ni siquiera se detenían. En un arranque de desesperación por lograr que se detuvieran, Karen, una maestra delgada y diminuta, se prendió de la puerta de la cabina de uno de estos camiones. Entre gritos e insultos, obligó al conductor a detenerse. Y lo logró, aunque éste último lo hizo únicamente para obligarla a bajarse. Todas observamos entre asustadas y sorprendidas por su valentía.

Considero importante aclarar que la ayuda de los maestros varones existe, y en algunos casos oficial; esto significa que se prioriza la seguridad de las mujeres, por ejemplo, es durante la formación de las marchas donde existe la técnica de "cuatro en fondo", esto significa que las maestras mujeres están al interior de las filas mientras que los maestros hombres hacen la función de valla para "protegerlas" de posibles agresiones. Cuando se desatan actos violentos, las mujeres son enviadas al campamento o se les pide que se dispersen, mientras que los hombres se quedan a enfrentar a la policía. Sin embargo, estos cuidados son en un sentido proteccionista, de infantilización y en muchas ocasiones la figura del compañero genera el mismo malestar y temor que la del policía en las mujeres. 


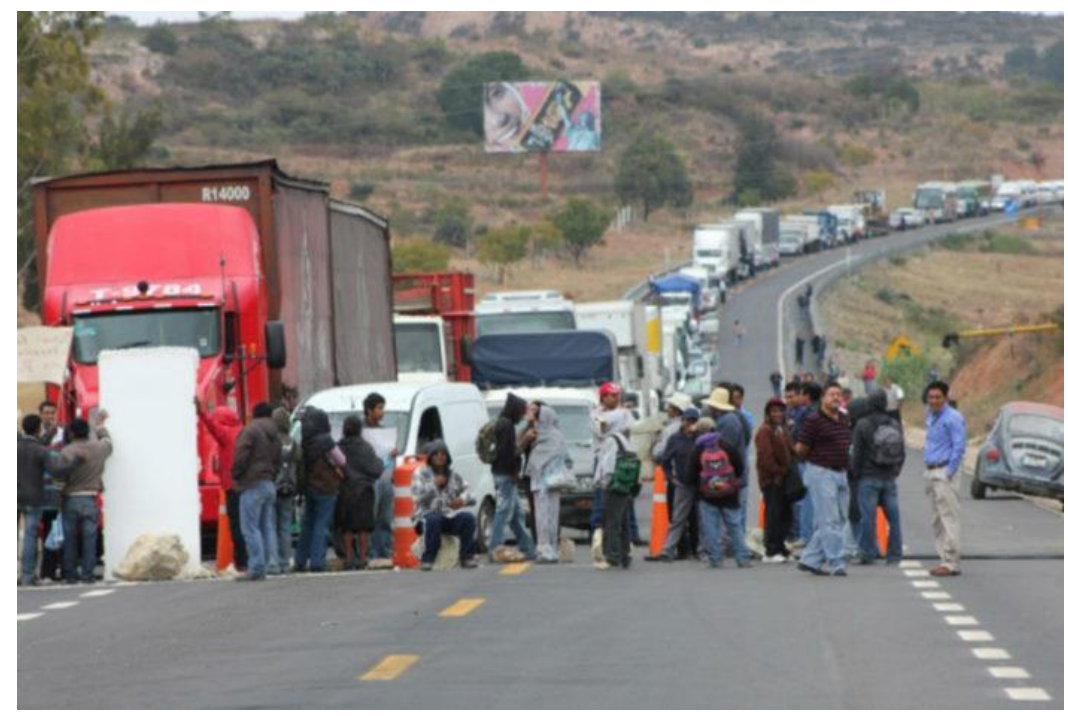

Bloqueo del Crucero Hacienda Blanca/ Junio 2006. Fuente: Periódico Noticias ${ }^{9}$

\subsection{Visibilizando la lucha femenina}

¡Muera el mal gobierno! ¡De norte a sur... de este a oeste... ganaremos esta lucha, cueste lo que cueste! ¡Educación gratuita para todxs! Son las consignas que siempre me ha gustado gritar: exigir la gratuidad de la educación. Durante una de las marchas, un profesor acusó a las mujeres de "histéricas" por gritar las consignas. Eso no es así, yo alzo la voz porque estoy harta de callar, porque tengo el derecho y la obligación de hacerme escuchar, porque soy un ejemplo para mis alumnxs y mientras esta lucha exista pelearé por defender lo que por derecho nos pertenece.

Guadalupe Pérez, 2019.

La máxima consigna del sindicato es jLa Sección XXII morirá el día que muera el sol! Yo afirmo que ¡La Sección XXII renacerá el día que la igualdad sea una realidad! La participación de las mujeres al interior de las organizaciones gremiales en México no es algo nuevo, desde la propia creación de los sindicatos las mujeres han trabajado junto a los hombres en la lucha por la defensa de los derechos laborales y de un trabajo digno. Sin embargo, la representación de las mujeres en los Comités Ejecutivos y en las instancias de gobierno de los sindicatos es, en varios casos, casi inexistente. En el caso específico de la

9 Autora: Citlalli Fuentes encontrada en oaxaca.quadratin.com.mx/continua-bloqueo-parcial-maestros$\underline{\text { hacienda-blanca }}$ 
Coordinadora Nacional de Trabajadores de la Educación, al ser esta una profesión feminizada, las mujeres conforman la mayoría de los agremiados, sin embargo, en los puestos de dirección esta mayoría no está representada. Al interior de la CNTE, dicha subrepresentación es evidente en la escasa participación de las profesoras de las estructuras representativas siendo particularmente notable en los ámbitos de máximo poder y decisión como son la dirigencia o coordinación. Claro ejemplo de ello es que, ahora mismo de los 36 puestos disponibles dentro del Comité Ejecutivo Seccional, únicamente cuatro son ocupados por mujeres, y que además están vinculados a ámbitos de gestoría social, cultura, recreación, la dirección de preescolar (CENCOS 2019). Los argumentos que mejor explican la menor presencia femenina en las organizaciones sindicales proceden de la propia cultura sindical, es decir, de la mayoría masculina que impera en el sindicato.

Tradicionalmente, las mujeres de la Sección XXII se mantienen en relaciones de subordinación. Sin embargo, es claro que ellas han desempeñado un papel central en el éxito que tienen las revueltas. A pesar de la poca confianza que se ha depositado en ellas, poco a poco las mujeres se van ganando los espacios y el respeto en las prácticas, demostrando su resistencia al frío, al hambre y al cansancio durante las marchas, caminatas, huelgas de hambre (Pérez 2015). Si bien es cierto, las maestras trasladan su papel doméstico al lugar del plantón: asean, cuidan, cocinan, tejen, bordan, también organizan, planean, resisten como han demostrado en actividades contundentes como fue la conformación de la CNTE en el año 1989 donde articularon el movimiento desde las comunidades. En 1994 resistiendo la suspensión de salarios impuesta por el gobierno federal como medida restrictiva por el paro indefinido de labores; en el 2006 como organizadoras de la toma de medios masivos de comunicación en la ciudad de Oaxaca que desembocó en la creación de la Comisión de Mujeres Oaxaqueñas (COMO) (Núñez 1990). En palabras de Soledad Cruz "Las mujeres somos la fuerza primordial del movimiento, tenemos la capacidad de hacer historia. Ahora es un orgullo decir que somos mujeres oaxaqueñas, la lucha ha fortalecido nuestra conciencia como ciudadanas; ya no somos sólo las administradoras del hogar: ahora estamos transformando la historia de Oaxaca" (Citado en Pérez,2015). En la investigación "Maestras oaxaqueñas: movimiento magisterial, vida cotidiana y democracia", queda de manifiesto que entre las profesoras existe una identificación de clase: 
Las maestras son de la corriente democrática por su extracción de clase porque les ha costado mucho trabajo llegar hasta donde se encuentran y han vivido en carne propia situaciones de injusticia y de desigualdad que han hecho que tomen conciencia. Por lo mismo existe un rechazo al abuso y la corrupción que da el poder. (Núñez 1990, 121).

Entre las maestras existen características definidas, a pesar de desenvolvernos en diferentes circunstancias existe un denominador común en nuestro actuar: el anhelo de mejorar nuestras condiciones de vida, laborales y la de nuestros alumnos. Muchas construimos nuestra identidad al interior de la misma lucha, es la descripción que a continuación realizo. 


\section{Capítulo 2. Marco metodológico-conceptual}

\subsection{Marco metodológico}

Mi proceso de concienciación de clase, raza y género lo viví poco a poco. Desde que era adolescente recuerdo haber escuchado sobre la lucha magisterial, los plantones y las marchas para exigir mejoras salariales y sociales. Los movimientos encabezados por maestrxs siempre han estado legitimados socialmente, parte de las conversaciones diarias tenían que ver con las demandas del gremio magisterial y las de autonomía y comunales de los pueblos oaxaqueños que en su mayoría están conformados por población indígena. A mi alrededor no había muchas personas que no fueran maestras, entre familiares cercanos y lejanos, vecinos y centros educativos, la rebelión social era un tema cotidiano y las experiencias de lucha siempre constituyeron una fuente de conocimiento y de concienciación comunal.

Seguramente influenciada por el contexto social en el que me desenvuelvo, es que decidí ser maestra y fue en mi etapa profesional — sin estar todavía plenamente consciente de esta relación - que advertí que mi rol de maestra rural vendría acompañada de lucha y resistencia social que no podía ignorar o pasar por alto. Mi participación en las protestas fue adquiriendo con el tiempo mayor compromiso con los ideales sindicales y de lucha de clases, me identifiqué con las historias de falta de oportunidades laborales, de polarización social que suele manifestarse en discriminación racial y represión a los sectores oprimidos que solían contarse en las reuniones gremiales o entre compañeros sindicalistas. Comprendí que yo era parte de esos grupos subalternos a pesar de haber accedido a la educación formal y tener una profesión, indicador de clase media en México. Sin embargo, la titulación académica no logra encubrir totalmente la actual crisis estructural que se vive en el país. Como señala Mohanty (2008) el lugar de enunciación determina la manera en que se viven y perciben las opresiones y en este caso, la forma en que se despliega la resistencia frente a los factores reales del poder.

En mis primeras participaciones sindicales me sentí acogida por mis compañeras maestras que militaban desde hace varios años y conocían la operatividad del sistema sindical, sus ventajas y desventajas. Ellas, más experimentadas que yo por su edad, conocían 
las propias relaciones de poder que se manifiestan dentro de la organización del gremio. En mi experiencia, tanto la agenda magisterial (conquistas sindicales y contenidos educativos) como la agenda social (que aglutina movimientos antisistema diversos) son el motor que impulsa la participación de lxs maestrxs y la solidaridad que surge entre las familias y lxs pobladores de las comunidades en las que trabajamos o a las que pertenecemos. El gremio se constituye en una comunidad que va más allá de la firma de un contrato laboral y la subsecuente afiliación sindical. La articulación de ambas agendas ha fortalecido la organización comunitaria de los pueblos oprimidos para expresar el descontento que resulta de siglos de marginación social, pobreza y corrupción política.

Sobre el desalojo del 2006 conocí sobre todo de la voz de mis compañeras. Aunque ya participaba en las marchas a las que convocaba la CNTE, fue de mis compañeras de quienes aprendí, aun sin haber vivido algo parecido, estrategias de resistencia, rutas de escape, evasión de policías y sobre todo de construcción de relaciones de solidaridad. De historias compartidas en diferentes foros, o incluso en las mismas marchas o plantones, aprendí de la unión entre pares, de empatía y de ayuda mutua. Aprendí que a las marchas y plantones no se acude sola, más bien, que una no se encuentra sola, aun cuando no conozca a las maestras con las que se marcha hombro a hombro, el trato es de iguales, de inmediato nos reconocemos como compañeras y la confianza crece conforme se vive la movilización. En varios de esos momentos de camaradería y rebelión, muchas de ellas me confirmaron que estaban dispuestas a dar su vida en el movimiento persiguiendo un ideal de justicia social, que no siempre alcancé a comprender dado las contradicciones políticas y la corrupción que pude advertir dentro del mismo sindicato.

Así, desde una perspectiva feminista, es necesario hablar de las historias que han permanecido ocultas, o más bien, que no han sido debidamente escuchadas, porque las maestras en México hemos hablado alto y fuerte para protestar y exigir nuestros derechos. Es entre nosotras que nos fortalecemos, nos formamos y nos informamos reconociéndonos como fuentes de conocimiento y poder. Esto ha generado que nuestra participación en los movimientos sociales se dé por hecho dentro de nuestras comunidades y acaso a nivel local. Fuera de estos ámbitos, nuestras experiencias y versión de los hechos no suelen ser difundidas o reconocidas. Los medios de comunicación se han encargado de reproducir un discurso de 
poder que nos invisibiliza como mujeres fuertes, organizadas y políticamente activas. Incluso, dentro del SNTE y la CNTE a los compañeros hombres les cuesta reconocer públicamente los roles que desempeñamos dentro del movimiento.

De acuerdo con Brooks y Hesse-Biber (2007) la documentación de las experiencias de las mujeres abona a la creación de un conocimiento desde la vivencia de opresión y de resistencia que da cuenta, no solo de la participación femenina, sino también de las estructuras opresivas en las que se desenvuelven sus actuaciones, enfocada por lo tanto a las problemáticas de las mujeres, a través de la documentación de sus experiencias, luchas y preocupaciones, analizando así las estructuras e ideologías que las oprimen. A partir de la década de los años sesenta, resultado de la concientización y esfuerzos de los movimientos feministas, las omisiones y exclusiones de las voces femeninas ha empezado a revertirse para ponerlas en el centro de la producción epistemológica recuperando los espacios que les habían sido negados en la historia oficial. En especial, la epistemología feminista, que propone a las mujeres como informantes privilegiadas que construyen nuevas narrativas desde el punto de vista de las opresiones sistemáticas, con la posibilidad de brindar tanto la perspectiva del poder como la de la opresión.

Este tipo de socialización que comenzó en mis primeros años de trabajo me permitió darme cuenta de la necesidad de hablar sobre los sentimientos y experiencias. Como señala Adrienne Rich (1987) esta necesidad de hablar no solo se centra en nuestras opresiones o condiciones de sumisión sino que se torna indispensable para reconocer nuestra presencia activa y nuestras prácticas como mujeres. Esta académica explica sobre la necesidad de hablar también de nuestras emociones y experiencias propias, de ella, entendí la importancia de escribir sobre mis vivencias personales formando parte del Sindicato. Reforzada por Adrianne Rich, "hablar donde el silencio ha sido aconsejado y aplicado". Como menciono anteriormente, son casi nulas las investigaciones y escritos que mi búsqueda me ha permitido encontrar sobre la temática que aquí abordo. Por lo que poner en el centro de la lucha magisterial las historias de las mujeres que resisten y se rebelan ante las opresiones, en tanto maestras y militantes, es una tarea pendiente en México. Son los dirigentes sindicales (en su casi totalidad hombres) los principales negociadores, las caras visibles y, por lo tanto, las historias androcéntricas desde donde se cuenta la lucha magisterial. 
Esta investigación parte de una epistemología feminista del punto de vista o standpoint theory en inglés que reconoce a las mujeres como punto de partida y que posibilita que nos situemos como figuras centrales en el proceso de investigación, basándonos en nuestras propias experiencias para la construcción teórica (Brooks y Hesse-Biber 2007; Harding 2002). En este caso parto de mis propias vivencias como mujer, maestra, miembro del sindicato y militante de la CNTE de la sección XXII del Estado de Oaxaca México. La razón por la que me sitúo desde mi propia actividad es porque la experiencia vivida tanto de las violencias y opresiones estructurales como de la resistencia en la que he participado devienen, por un lado en una oportunidad para difundir la participación de las mujeres como un primer acercamiento a las historias de las maestras militantes, y por otro lado, como una práctica de liberación personal que puede servir a otras maestras y/o militantes ya sea para explorar críticamente y reflexionar sobre los diferentes puntos de vista, desde la voz de la resistencia, sobre un mismo evento, o para ponerlo en común en un futuro, también como una práctica liberadora.

Lo que es más, hacer este trabajo desde la mirada autoetnográfica me ha permitido rememorar experiencias y vivencias pasadas, pero esta vez, desde la teoría y sobre todo con una mirada feminista. Me he sentido cercana a las sensaciones que bell hooks (1991) describe acerca del santuario que encontró al teorizar a fin de encontrar sentido a sus vivencias, es decir "encontrar en la teoría un lugar sanador".

A decir de Butler ([1993] 2011 pág. 522): "lo personal es implícitamente político en la medida en que está condicionado por estructuras sociales compartidas, pero lo personal también ha sido inmunizado contra el desafío político en la medida en que las distinciones público/privado perduran". En este sentido, para el feminismo lo personal cobra relevancia ya que se encuentra inserto en las estructuras políticas que se viven en el plano de lo que tradicionalmente se ha identificado como el ámbito público. Nuestras propias experiencias, como sostiene Kate Miller y luego Judith Butler, no son únicamente casos aislados, sino que suelen ser un caso más de una opresión sistemática que sufrimos las mujeres en el sistema patriarcal. El principio de "lo personal es político", refiere así que aunque hablemos de historias personales, estas se convierten en "categorías expansiva, que se adapta, aunque solo sea implícitamente, a las estructuras políticas generalmente consideradas públicas” (Butler 
[1993] (2011), pág.522). Mi experiencia, por tanto, puede ser compartida por muchas mujeres que hasta ahora no han podido expresarlo mediante un texto académico, al que ahora yo tengo acceso debido a mis estudios de posgrado en el extranjero gracias a una beca, situación que no suele ser el común denominador en la región oaxaqueña y que reconozco como un privilegio.

Harriet Jacobs cuenta, desde una narrativa autoetnográfica, sobre su experiencia como esclava en el sur de Estados Unidos. En sus escritos, confiesa no haber escrito por el placer de atraer la atención hacia ella, al contrario, hubiera preferido no tener que contar su historia. No obstante, el objetivo para ella consistía en la necesidad de denunciar el sufrimiento y la precariedad de la situación de personas que como ella, vivían en situación de esclavitud (Brooks y Hesse-Biber, 2007). Y es que no es siempre fácil recordar y escribir sobre las experiencias difíciles o traumáticas vividas. Sin embargo, al igual que para Jacobs, escribir desde la propia experiencia puede llegar a ser casi una obligación. Por consiguiente, no es mi intención llamar la atención sobre mi persona, más bien, pretendo evocar a través de mi vivencia los actos de dominio que la estructura estatal ejerce sobre nuestros cuerpos militantes, ya que la represión es la principal arma del Estado contra los actos de resistencia en las protestas masivas.

En los actos de protesta se evidencian de igual forma los lazos de sororidad que se tejen entre mujeres militantes, en este caso del gremio magisterial. Para transmitir y comprender el aspecto social y feminista de esas experiencias, tanto opresivas como de resistencia sororal, acudo a la autoetnografía feminista (Acevedo 2007; Blanco 2012) como método de escritura y de transmisión de las historias de lucha a las que tuve acceso por medio de las compañeras que compartieron conmigo y de las que yo misma fui partícipe.

La autoetnografía supone el relato de experiencias relevantes para la investigación a las que de manera retrospectiva y explicativa se acude para informar aquello que siendo personal tiene un impacto social y cultural (Blanco 2012). Aspiro en este ejercicio a desentrañar cómo de las experiencias personales se puede extraer información valiosa desde un enfoque feminista a fin de explorar cómo es que se tejen las relaciones de sororidad en las prácticas propias de las movilizaciones sociales. Entendida la sororidad, según se explicó antes, como una herramienta relacional con una base ética de cuidados mutuos y de 
producción de vínculos que conllevan fines políticos. Las historias personales narradas aquí nutridas a partir de un enfoque feminista buscan contribuir a un replanteamiento de la historia contada por las élites de poder encarnadas principalmente en los hombres y el Estado.

Miller y Swift (1976) citadas por (Campos 2012) propusieron la construcción de la her-story como medio para contestar a la postura parcial del his-story que ha invisibilizado los diversos roles de las mujeres y su participación en la historia, con la finalidad de reconstruirla a partir de los ojos y relatos de las mismas mujeres, constituyendo así un enfoque útil para los propósitos de la investigación feminista basada en el punto de vista de los sectores oprimidos. Como bien ha apuntado (Campos 2012)), hablando sobre los relatos de las mujeres en la academia, cuando nos apropiamos de nuestras experiencias y las resignificamos potencializamos nuestras tácticas de supervivencia que a su vez generan oportunidades para otras mujeres de recrear sus propias historias. Aplicado al ámbito de las movilizaciones sociales, es importante destacar que además de estrategias de supervivencia se potencia la creatividad de relacionarnos de maneras diferentes a la hegemónicas o a las dictadas por la tradición patriarcal. Es decir, en los mismos intercambios de relatos se generan nuevas formas de relacionarnos entre mujeres, en las que aprendemos a identificarnos como iguales, a trazar nuevos vínculos e intencionalidades políticas influyendo de manera valiosa en la vida de cada una y probablemente en la de otras mujeres que compartan nuestro contexto específico.

Para producir los relatos me centraré en la metodología que propone Teresa del Valle (2017) para acceder al estudio etnográfico del pasado cuando emerge de la reflexión autobiográfica. La evocación, la preexistencia y el pasado son los elementos que distinguen esa metodología reflexiva. De acuerdo a la autora, la evocación consiste en el acto de traer al presente personas, acciones, pensamientos, vivencias y emociones las cuales se activan dentro de un marco contextual donde cobran sentido. En este aspecto, el contexto se limita a los hechos del desalojo contra el plantón de la CNTE del SNTE que viví en el año 2013 y algunas evocaciones del desalojo del 2006, que como se verá no pueden separase de acuerdo a los términos del elemento de preexistencia. La preexistencia implica la superposición de dos o más eventos o elementos que se diferencian entre sí pero que se identifican o interpretan necesariamente debido a su relación. 
Por tratarse de eventos históricos, concatenados social, cultural y políticamente, el movimiento del 2013 no puede explicarse sin el antecedente del 2006, en el cual no participé directamente pero que no puedo dejar de evocar dado las veces que mis compañeras, quienes sí lo vivieron, me compartieron y al cual puedo referirme con cierta naturalidad como resultado de lo que aprendí de dichas experiencias. De hecho, considero que estos dos eventos son en sí mismo productos del contexto socio-cultural específico del Estado de Oaxaca que no pueden leerse ni entenderse de manera aislada. Finalmente, éste último punto tiene que ver con el pasado, el cual "pasa a ser un sin control e ilimitado" (Del Valle 2017, pág. 44) sujeto al control político y cultural. Lo cual refuerza que al tratarse de una construcción social, es de importancia reapropiarse del pasado para que tengamos cabida en él como mujeres sororas y luchadoras sociales, reconduciendo a la idea inicial: los relatos personales nos permiten politizar eventos del pasado que pueden ser comunes a muchas mujeres que pueden beneficiarse de la reproducción de relatos de sororidad y cuidados entre iguales para resistir los poderes opresores.

A continuación, en el siguiente apartado expongo el contexto en el que sitúo mis experiencias en el denominado "desalojo del 2013 de la Cd. de México”, ya que como mencioné antes, se facilita la comprensión de un acontecimiento y los recuerdos producidos en éste, de igual forma, coadyuvará a que las evocaciones cobren sentido para el/la lector/a dentro de un espacio-tiempo cultural y social determinado.

\subsubsection{Delimitación contextual}

Lo que había comenzado a finales de los años setenta como una marcha contra los retrasos en pagos de salarios a lxs maestrxs devino en la exigencia de mejoras en las prestaciones, la construcción de nuevos liderazgos político-sociales y la ocupación del espacio público como plataforma política donde las mujeres cobran especial relevancia no solo en el espacio sino con repercusiones a nivel nacional. Las movilizaciones magisteriales de los años 2006 y 2013 han marcado un hito en la forma en la que hombres y mujeres de todas las edades (muchas mujeres acompañadas de sus hijxs en brazos o en edad preescolar), obreros, campesinos, estudiantes, etc. se aliaron a la protesta magisterial para repeler el poder político-policial que con lujo de violencia reprimía a lxs alzados. Haciendo a un lado las alianzas que se crearon entre el sindicato y el gobierno en turno para golpear y fracturar la 
organización popular que estaba logrando una fuerza insospechada en ambos momentos, lo que nosotroxs como maestrxs identificamos como "la venta del movimiento a los poderosos" o "la traición de los líderes sindicales", lo que me interesa rescatar es la voluntad, fortaleza y lucha digna que las maestras y muchas mujeres aliadas sostuvieron el movimiento hasta el último momento a pesar de lo cruentas que eran las represiones.

En el año 2006, más de setenta mil maestrxs se enfrentaron por más de siete horas al desalojo ordenado por el Gobernado Ulises Ruiz. El exceso de fuerza policial no impidió la retirada de la policial y el reagrupamiento de los maestrxs, a quienes se sumaban cada vez más simpatizantes de organizaciones sociales, civiles y políticas. La Asamblea Popular de los Pueblos de Oaxaca (APPO), que englobó a las diferentes organizaciones, exigió la destitución del Gobernador del Estado cobrando nuevas dimensiones políticas que alcanzó la intervención de las autoridades federales. En un nuevo enfrentamiento, los integrantes del magisterio y de la APPO respaldados por la sociedad civil fueron desalojados por las fuerzas federales y replegados a las instalaciones de la Universidad Autónoma de Oaxaca. Un grupo de mujeres de la APPO quienes se habían apropiado de las instalaciones del Canal de televisión del Gobierno del Estado, y desde donde llamaban a la resistencia, también fueron expulsadas.

La jornada violenta dejó un saldo de tres personas asesinadas por armas de fuego, centenares detenidas arbitrariamente y varios desaparecidos. La reacción al autoritarismo estatal evidenció la cohesión social y el espíritu revolucionario de lxs oaxaqueños, los actos de resistencia y ofensiva se mantuvieron al menos una semana más exigiendo la renuncia del gobernador, la retirada de la policía federal y la presentación de los desparecidos y presos políticos.

Siete años después, en el 2013, el conflicto magisterial se reavivó con las reformas estructurales del gobierno federal que propusieron un modelo educativo centralizado que invisibiliza las necesidades de la pluralidad oaxaqueña que alberga 18 grupos étnicos los cuales representan más del 32\% del total de la población total en el estado (Cisneros 2006). Las prácticas de autonomía política que se dan desde tiempos revolucionarios en diferentes comunidades del Estado no comulgan con las intenciones del gobierno de Enrique Peña Nieto (quien gobernó México de 2012-2018) de definir el contenido de la educación a nivel 
nacional, además de las afectaciones laborales que ocasionarían las evaluaciones a los maestros para asegurar una supuesta calidad basada en estándares alejados a la realidad socioeconómica de los pueblos de Oaxaca. La sección XXII del SNTE exigió la participación en la definición de los contenidos educativos. Estas exigencias han sido traducidas por los medios de comunicación y las autoridades como una negativa a las evaluaciones, que tendrán como efecto el despido de aquellxs maestrxs que no superen las pruebas, que responde más al espíritu conformista atribuido desde las esferas del poder a los pueblos marginados.

De acuerdo con Ramírez (2016) la reforma constitucional de 2013 enfrenta dos perspectivas, la visión comunitaria y la visión del nacionalismo homogeneizante, es decir, la reforma educativa-laboral versus el Programa de Transformación Educativa de Oaxaca (PTEO), la educación para la producción versus la educación para la liberación social. Las mesas de negociación entre ambos proyectos se centraron en el aspecto de la evaluación docente, la educación indígena y contenidos sociales para las comunidades. Las carreras por el poder político en las elecciones locales gubernamentales han influido las demandas y las protestas sindicales y sociales, tanto en el 2006 como en el 2013, lo cual vela el panorama y encubre las corruptelas y negociaciones políticas que se filtran al interior del sindicato y de ahí al movimiento. Lo anterior, muchas veces no permite que se distingan las demandas sociales y sindicales de base, de los maestros de pie como yo, lo que ha ocasionado que los ideales de liberación y de justicia se vean manchados por los malos manejos de algunos líderes sindicales y se desprestigie la protesta social honesta.

\subsubsection{Estructura de los relatos}

Como he explicado en el marco metodológico los relatos son evocaciones de mi participación en el conflicto magisterial del 2013, y los recuerdos de las charlas y testimonios de algunas compañeras que vivenciaron las manifestaciones del 2006. Están redactados en primera persona, diferenciando con letras cursivas los que no viví de manera directa. Considerando el asedio y persecución de la que es objeto la lucha magisterial he decidido utilizar nombres ficticios de las maestras involucradas, esto con el fin de protegerlas ante el peligro a la que estamos expuestas. Aún así considero valioso describir aspectos relevantes de su personalidad y mi cercanía con ellas, con el fin de recrearlas en el imaginario de lxs lectorxs: Alma, luchadora social desde hace 20 años, fue quien me enseñó las rutas de escape 
y cuidado en mis primeras manifestaciones; Alicia, docente de preescolar creativa y combativa. Aurora, activista política asediada y perseguida por encabezar la toma de las televisoras y radiodifusoras locales. Ana, compañera y amiga la conocí durante un plantón en la Ciudad de México, 5 años menor que yo, le enseñé las rutas de escape.

Quiero señalar que la aspiración de esta investigación en ningún caso es la de universalizar lo que aquí relato, ya que esto no es ni posible ni deseable. Imposible porque las identidades de estas mujeres son tan ricas y distintas como mujeres componen la lucha, e indeseable porque no pretendo en ningún caso la imparcialidad en mi relato. Reconozco así como un valor de la misma que las historias y experiencias que aquí narro están enraizadas en cuerpos de mujeres únicas y diversas, indígenas, oaxaqueñas, madres, solteras, casadas... De este modo, cedo a lxs lectorxs de este trabajo la decisión de reflejarse, identificarse, enfrentarse u ofuscarse con lo que yo, desde mi posicionamiento, siento y expreso.

\subsection{Marco conceptual}

Al ser el objetivo de esta investigación, la identificación de las relaciones de sororidad como estrategias de cuidado y resistencia entre las maestras activistas de la Sección XXII dentro de la CNTE, encuentro imprescindible abordar los conceptos claves. Por lo tanto, en el presente capítulo, teorizaré en una primera instancia, el concepto de sororidad. En la misma línea, analizaré en una segunda y tercera parte las nociones de resistencia y empoderamiento a fin de dar un marco teórico y conceptual a este trabajo autoetnográfico.

\subsubsection{Sororidad, una alianza inquebrantable}

El término sisterhood fue propuesto a finales de los años 60 por la escritora estadounidense Kate Millett conocida principalmente por su obra Política sexual (1960) y una de las principales referentes del feminismo radical de la segunda ola. En una primera definición la sororidad hace referencia a la amistad entre mujeres diferentes y pares. Así, sororidad es una palabra para designar las relaciones que se establecen entre mujeres. Lo que da un alcance peculiar a las mujeres es la fuerza, unidad y pluralidad. Un tránsito entre los 
niveles de afirmación de la subjetividad en lo grupal, a través de una experiencia colectiva que permite construir un nuevo espacio de experiencia basado en las actividades conjuntas (Posadas 2008).

Si bien, el término surge en la segunda ola del feminismo, donde las americanas lo nombraron sisterhood, las francesas sororité y las italianas sororita, este concepto va tomando su forma entrelazado con momentos, luchas y otros conceptos como el propuesto por las feministas italianas de affidamento, que alude a una relación entre mujeres semejantes, dispares y diversas donde se reconoce autoridad femenina y se deposita en ella la confianza. La sororidad es un concepto que surge en "la necesidad de una mediación sexuada femenina y no masculina como hasta entonces" (Posadas 2008). Por ejemplo, cuando en El Segundo Sexo Simone de Beauvoir (1949) alude al término de fraternidad, da cuenta de cómo la mujer queda excluida en los pactos patriarcales, ya que es ahí donde se fraguan los pactos que perpetúan la desigualdad de género, y entonces sugiere la conformación de una relación que considere a las mujeres como agentes en vez de ser un objeto pactado dentro de los acuerdos de la fraternidad. Una de las autoras que menciona con más fuerza el concepto de sororidad, es la activista mexicana Marcela Lagarde (2012). Ella presenta el término no solo como una búsqueda de alianzas, sino que va más allá, dándole una dimensión de práctica política:

La sororidad es una dimensión ética, política y práctica del feminismo contemporáneo. Es una experiencia de las mujeres que conduce a la búsqueda de relaciones positivas y a la alianza existencial y política, cuerpo a cuerpo, subjetividad a subjetividad con otras mujeres, para contribuir con acciones específicas a la eliminación social de todas las formas de opresión y al apoyo mutuo para lograr el poderío genérico de todas y al empoderamiento vital de cada mujer (Lagarde, 2012, p.560).

Para Lagarde, la sororidad es un pacto político que busca enfrentar las opresiones sobre las mujeres, basado en el reconocimiento de la diferencia. Asimismo, reconoce el componente afectivo entre las mujeres, quienes se fortalecen a través de las acciones colectivas (Lagarde, Claves feministas para el poderío y la autonomía de las mujeres 1997, 31). Por su parte, Olaya Fernández (2010) afirma que, para alcanzar una verdadera transformación social, las mujeres debemos realizar procesos de resistencia y empoderamiento, procesos donde la diversidad femenina y nuestras relaciones sororales supongan una alternativa a los discursos dominantes que han conformado nuestra 
subjetividad. Es de esta forma que será posible la articulación de una nueva cosmovisión cultural. No se trata de buscar nuestro lugar en un mundo hecho a la medida de los hombres, sino de crear un mundo diferente e igualitario (Fernández, 2010, pág. 54). De esta manera, al interior de la sección XXII, las relaciones sororales se superponen. Sin acuerdos escritos o pactos entre nosotras, las mujeres creamos redes de ayuda no visibles pero firmes, nunca dichas pero ejecutadas, a través de pequeñas acciones como la búsqueda de sanitarios hasta grandes hechos como la resistencia a los granaderos.

Desde la perspectiva comunitaria la activista boliviana Julieta Paredes en su libro "Hilando Fino desde el Feminismo Comunitario" habla sobre la posibilidad de crear en comunidad y lograr la cooperación entre grupos de mujeres, mientras se respetan las diferencias individuales como una forma de visibilizar todos los tipos de mujeres con sus particularidades sin encubrir raza, clase, escolaridad: "Nosotras partimos de la comunidad como principio incluyente que cuida la vida. Para construir redes comunitarias es necesario desmitificar las dicotomías que nos impide analizar la realidad de la vida de las mujeres en nuestro país" (Paredes 2010, 79) A través de la complicidad y cooperación, es evidente que las mujeres generan fuerza cuando trabajan en conjunto, ayudándose unas a otras.

En este sentido considero importante aclarar que mi intención no es caer en un esencialismo ni romanticismo de la idea de sororidad y apoyo entre mujeres, en varias ocasiones la teoría feminista ha demostrado las diferencias que permean entre nosotras; lo que pretendo en esta investigación es demostrar que las alianzas, reflejadas a través de los actos sororales y de cuidados entre mujeres, han mejorado la situación de las mismas durante las situaciones de vulnerabilidad en las que nos veíamos expuestas durante las movilizaciones del sindicato.

Por otra parte, aunque Lagarde, Martínez y otras feministas contemporáneas utilicen esta palabra como un símbolo de solidaridad femenina, en su libro "The Politics of Third Wave Feminisms: Neoliberalism, Intersectionality, and the State in Britain and the US" Elizabeth Evans (2015) menciona cómo el término sisterhood puede convertirse en un concepto que disfrace el hecho de que muchas mujeres con cierta cuota de poder, explotan y abusan de otras mujeres; especialmente desde formas racistas y clasistas. Esta es una de las críticas que recibe el concepto sororidad por ser un término asociado a mujeres blancas, 
burguesas, de clase social media-alta y que en algunos usos puede aparentemente no tener un sentido político. Sin embargo, contrario a lo que Evans discute sobre sisterhood viéndola como una etiqueta engañosa, la sororidad entendida nuevamente desde Lagarde y como la entenderé yo en este trabajo, es una oportunidad para formar lazos de unión con otras mujeres, para acompañarnos y apoyarnos, creando espacios de solidaridad y respeto, donde se hile bajo el concepto de la comunidad y la colectividad. El feminismo nos exhorta a minimizar nuestras diferencias y potencializar nuestros nodos en común, esto con la finalidad de poder entender a la otra y buscar mejores condiciones de vida para todas.

Por esta razón y para fines de la investigación asumo el contenido que Lagarde (2012) asigna a la sororidad descentrándola de una sujeto mujer, blanca, burguesa, del norte global para enfocarla hacia una comunidad de maestras militantes en igualdad de circunstancias. Como parte de las acciones de sororidad, también se generan convergencia, apoyo y ayuda, entendiendo que todos los sujetos que forman parte de los pactos solidarios pueden a su vez ser solidarios en otro momento. Así, no es un acto de caridad ni asistencialismo, sino se trata de un principio democrático de intercambio (Lagarde, 1997, pág. 47).

Ahora bien, para el análisis retomo las tres dimensiones, explicadas anteriormente, presentes en las relaciones de sororidad: la ética, la política y la práctica. Desde mi experiencia puedo decir que el nivel ético se encuentra en la intención de apoyo mutuo y de cuidados que nos procuramos entre maestras reflejando alianzas de género temporales o duraderas "cuerpo a cuerpo, subjetividad a subjetividad". La dimensión política se expresa en las aspiraciones de liberación de las prácticas de opresión encabezadas por el Estado, y de exclusión hechas por el mismo sindicato; a la par que se va construyendo el poder político de las mujeres militantes que se facilita a través del acompañamiento entre nosotras. La parte práctica se presenta como "un hacer", un conjunto de acciones específicas que contribuyen a la creación de alianzas y al empoderamiento de las mujeres participantes. Esta dimensión se percibe en dos niveles, el subjetivo, que es la intención que tiene la creación de la práctica y el nivel material, que es la puesta en acción de esa intención. Al respecto, es importante recordar que la política y la ética son moldeadas por prácticas de resistencia y estrategias cuyo fin último es la generación de espacios políticos seguros, habitables, creativos y plurales. 
Como detallaré más adelante, las mujeres son víctimas frecuentes de la violencia de género en el trabajo, instaurada a través de procesos de segregación, hostigamiento y acoso por eso considero imperativo señalar, esa como la razón de la ausencia de los hombres.

\subsubsection{Prácticas de cuidados}

Cuando se habla de cuidados desde un enfoque feminista, lo más común es entenderlo desde la teoría que trabajan académicas como Marcela Lagarde, quien asocia este acto con un aprendizaje patriarcal impuesto a las mujeres, que limita su propia autonomía:

(...) en la condición patriarcal de las mujeres no hay autonomía, por principio, pues se trata de una construcción de género en la que las mujeres somos habilitadas para hacernos cargo de la vida de otras personas. A este hecho lo he llamado "ser para cuidar vitalmente a los otros". Somos las cuidadoras de todo el mundo; tenemos como función vital: dar la vida, protegerla, cuidarla, reproducirla y mantener a las personas concretas en las mejores condiciones posibles. Por eso es estructuradora de la condición tradicional de la mujer; sintetiza la ética del cuidado. ¿Qué es lo más importante de la vida en la vida de una mujer? Cuidar y seguir cuidando y volver a cuidar a otras y otros, toda la vida, de día y de noche, para toda la vida. ¿Cómo? De múltiples maneras, social y culturalmente determinadas: por roles, por funciones, por espacios. La semejanza de las mujeres, en la cultura y en la sociedad patriarcal, está dada por el cuidado vital de los otros (Lagarde, Claves feministas para el poderío y la autonomía de las mujeres 1997, 20).

En este sentido, históricamente la responsabilidad de los cuidados de los miembros de la familia ha sido asignada a las mujeres. Es ésta quien ha sido educada y moldeada socialmente para hacerse cargo de los demás, asegurando siempre su bienestar y muchas veces sobreponiendo el bienestar de los demás ante el suyo propio. Por lo tanto, parecería que la acción de cuidados son sólo un reflejo de este rol sociocultural impuesto. Sin embargo, los actos de cuidado pueden tener también otros enfoques más positivos. La académica Irene Comins asocia la ética de cuidado como un aporte para la transformación pacífica de los conflictos entre los seres humanos. Así, a pesar de coincidir con Lagarde con que 
históricamente han sido las mujeres quienes han cumplido con el rol de cuidadoras como un constructo social aprendido $(2007,93)$, para esta autora, los cuidados pueden tener grandes aportes a la sociedad:

La ética del cuidado está muy en relación con la importancia de potenciar los vínculos personales, elemento que disminuye la aparición de conflictos y facilita la transformación de los existentes (Comins 2007, 95).

Comins entiende que hay una razón moral que lleva a las mujeres a asumir estos cuidados, quienes han aprendido a dar mayor importancia a las relaciones interpersonales y a los individuos de manera concreta, a diferencia de los hombres, quienes se concentran en otros aspectos como el cumplimiento de las normas. Sin embargo, estos cuidados permiten generar y mejorar las relaciones personales así como gestionar los conflictos de una mejor manera. Es en esta línea que la teoría de cuidado cobra sentido en la presente investigación, al reforzar la idea de que los actos de cuidado han sido y son parte de las alianzas sororales de las mujeres de la sección XXII de la Coordinadora Nacional de Trabajadores de la Educación, que explicaré en el siguiente capítulo.

\subsubsection{El empoderamiento}

El neologismo empoderamiento ha sido acuñado como una categoría de análisis social para referirse a procesos por los cuales sujetos subalternos logran poder, entendiendo dicho poder como capacidad para manejar la propia existencia y para definir los propios proyectos de vida, dos exigencias ineludibles en orden a que dichos sujetos puedan abrir(se) espacios de participación social, transformando así su situación de subordinación y logrando ser sujetos políticos (Riba 2016). Vinculando el empoderamiento a las mujeres, comentan Virginia Azcuy y Marta Palacio:

El empoderamiento de las mujeres -término que proviene del inglés empowerlempowerment-, en cuanto capacidad de acción, es una práctica feminista que tiene que ver con la posibilidad de las mujeres de tomar la palabra e incidir en la acción política colectiva a través de constituir redes entre sí. Como modo de construir poder a través de los pactos o alianzas críticas entre mujeres, el empoderamiento es una práctica 
que pretende contrarrestar la dispersión y confinación atomizada en los espacios privados, causa histórica de la debilidad política de las mujeres dentro de la estructura patriarcal (Azcuy y Palacio, 2008; en Riba, 2015, pág.241).

En el caso específico del empoderamiento de las mujeres, la sororidad es un camino fundamental, como apunta la misma Azcuy (2008); empoderarse implica establecer relaciones de solidaridad, hermandad y cooperación entre mujeres, de tal manera que haciendo pactos puedan constituirse en sujetos políticos capaces de producir nuevas alianzas y discursos distintos a los del patriarcado; lo anterior, aprovechando las capacidades, los bienes, las oportunidades, los recursos a favor de una misma y, en el caso de las maestras militantes por ser una experiencia colectiva, a favor de muchas. Alude entonces a un proceso de toma de conciencia individual y colectiva de las mujeres, que les permita aumentar su participación en la toma de decisiones, individual y colectiva de las mujeres, y de acceso al ejercicio de poder y a la capacidad de influir en el cambio social, tanto a nivel individual como colectivo. Esto implica, descubrir en las prácticas sororales establecidas en la Sección XXII las formas de acceso al poder y representatividad que hasta el momento nos han sido negadas. En este sentido, considero que la necesidad primaria para el empoderamiento es el reconocimiento de la fuerza que las maestras tenemos al interior del magisterio, de los cambios que se han gestado a con nuestras luchas y ver en ellas la posibilidad del cambio, como Magdalena León señala:

[...] el empoderamiento puede ser una simple y mera ilusión, si no está conectado con el contexto y se relaciona con acciones colectivas dentro de un proceso político(...) El empoderamiento incluye tanto el cambio individual como la acción colectiva...debe integrarse en un sentido de proceso con la comunidad, la cooperación y la solidaridad. $\mathrm{Al}$ tener en cuenta el proceso histórico que crea la carencia de poder, se hace evidente la necesidad de alterar las estructuras sociales vigentes; es decir, de reconocer el imperativo del cambio [...] (M. León 2001, 98), 


\section{Capítulo 3 Los relatos: iTodas somos compañeras! Las relaciones sororales en la Coordinadora Nacional de Trabajadores de la Educación}

\subsection{Mi perspectiva y vivencia (memoria, recuerdos)}

Desde niña tuve claridad respecto a mi vocación: deseaba ser maestra y lo conseguí, concluí mi formación como licenciada en docencia en la Universidad Autónoma del Estado de Morelos y en el año 2009 inicié como maestra rural en la Sierra Sur de Oaxaca. Es así que, de manera automática, formé parte de la Sección XXII, es decir del SNTE y la CNTE al mismo tiempo. Ingresar al magisterio con 22 años marcó un hito en el sentido que Teresa del Valle lo expresa: aquellas decisiones y vivencias que al recordarlas se constituyen en una referencia significativa; reconocidas en el momento en el que se producen o a posteriori con la reflexión y el recuerdo (1995, pág. 244).

El primer centro de trabajo en el que laboré en aquel año fue la Escuela Secundaria Técnica 129 de San Pedro Mixtepec, Miahuatlán en la Sierra Sur de Oaxaca, una comunidad marcada por la pobreza, el olvido del gobierno estatal y el narcotráfico. La escuela estaba provista del material estrictamente necesario: pizarrón, butacas y un pequeño escritorio, no contaba con biblioteca y, a pesar de que el inglés formaba parte del currículum como materia obligatoria no había diccionarios o material de apoyo para reforzar los contenidos, el aula de informática contaba con dos computadoras que funcionaban sólo cuando había luz eléctrica y la urgencia de un comedor escolar era evidente. Los días lunes, durante los honores a la bandera a primera hora de la mañana en el patio de la escuela, el cual duraba escasos diez minutos, lxs alumnxs solían desmayarse pues la mayoría de ellos no había desayunado. La lengua materna de mis estudiantxs era el zapoteco, habían pasado de un sistema de educación primaria bilingüe a uno de secundaria sólo en español y las dificultades para comunicarse eran notorias. Ahí descubrí el abismo entre teoría y práctica, entendí que los encargados de diseñar los programas de estudio nunca habían puesto un pie en una escuela de la Sierra Sur, ni en ninguna otra, dicho sea de paso.

Viví en carne propia la más profundas de las austeridades y sentí impotencia ante las injusticias. No solo por mis alumnxs, también por mí y mis compañerxs de trabajo. El salario quincenal que percibía apenas alcanzaba para cubrir los gastos de transporte, estancia, 
comida, material didáctico. Sin contar las distancias recorridas cada fin de semana. San Pedro Mixtepec se encuentra a $300 \mathrm{~km}$ de la capital que representan ocho horas de transbordar en camionetas y autobuses. La situación empeoraba para quienes, además, debían sostener una familia pues tenían que buscar actividades que les ayudaran a complementar los ingresos (ayudantes de albañil, venta de productos de belleza, para el hogar, por catálogo, entre otras). Ante este panorama, aún sin conocer el modus operandi de la Coordinadora Nacional de Trabajadores de la Educación y sin experiencia previa en actividades de protesta se forjó en mí una conciencia política que, como detallé en el marco metodológico, me incitaba a participar de manera genuina. Es, además un sentimiento generalizado, en palabras del periodista Luis Hernández Navarro (2006): "si hay un sector en la población que se ha movilizado constantemente, ese es el sector educativo oaxaqueño y dentro de éste, maestras y maestros han recorrido todas las calles del país enarbolando sus demandas; han cerrado las avenidas más importantes de las capitales para defender su salario y sus programas educativos, para lograr algunos recursos extras que hacen falta en las desvencijadas escuelas públicas mexicanas".

Al interior de la Coordinadora existen corrientes políticas, algunas de ellas cooptadas por el partido en el poder, otras de nueva creación y una, que me cautivó por estar liderada por una maestra que laboraba en mi zona escolar. María ${ }^{10}$ era una maestra reservada, de carácter fuerte, y de pocas palabras, más tarde supe que era perseguida y acosada por el Estado. Después de coincidir en una asamblea en la que fungí como vocera del centro de trabajo, se acercó a mí para ofrecerme ingresar a su grupo. Excitada por la idea de formar parte de un colectivo, quedamos de acuerdo para conversar e intercambiar ideas. Lejos de una reunión planeada, el encuentro se dio en medio de un plantón en la Ciudad de Oaxaca, en un sitio informal, de forma clandestina y fugaz. Fue una experiencia impactante, la presentación de lxs integrantes era en función de su lucha política: viuda del dirigente, madre del activista desaparecido, esposa de preso político, hermano de perseguido. Este episodio es significativo en medida que me ayudó a asumir mi propia posición política en la lucha sindical. No tuve el valor para adherirme al colectivo relatado porque sentí miedo, como

\footnotetext{
${ }^{10}$ Como mencioné en el apartado metodológico, para proteger la confidencialidad de los personajes sus nombres y el de las agrupaciones son ficticios.
} 
menciono previamente, no miedo de morir, pero de desaparecer y que mis padres tengan que buscarme. Pero desde entonces asumí una posición de activista, desde donde ahora me enuncio.

Poco a poco fui entendiendo la dinámica de las protestas, la forma de involucrarme y los riesgos e implicaciones. Descubrí también el clientelismo enraizado en la Sección XXII del Sindicato, el acoso de los compañeros, el hostigamiento de los líderes sindicales a las maestras; en suma, entendí lo que representaba ser mujer, joven y de nuevo ingreso en un sindicato patriarcal. La mayoría de las amistades que forjé en aquellos años fueron con mujeres, algunas permanentes otras temporales, todo dependía del tipo actividad en la que coincidíamos. Como estrategia de autocuidado, me relacionaba sólo con ellas, el acoso constante de los compañeros me provocaba temor y desconfianza. Con el paso de los años y el cúmulo de experiencias caí en cuenta que las maestras habíamos ideado estrategias de resistencia para soportar el embate de los policías, pero en la misma medida las habíamos creado para protegernos de los hombres al interior de la Sección XXII. Dichas estrategias iban desde cuidar la entrada de las casas de campaña a la hora de vestirnos o cambiarnos de ropa, mantenernos unidas en escenarios de violencia, dormir juntas o cerca para evitar cualquier intromisión en las carpas e incluso, en mi caso, tener una pareja sentimental dentro del gremio para librarme del machismo magisterial. No estoy segura si lo que sentía era amor por mi pareja -qué es el amor, en cualquier caso-, pero sí sé que mi proceso de concienciación feminista ha iluminado el recuerdo y ahora reconozco que, en ese momento, nombrarme como la pareja de $\mathrm{x}$ hombre era la manera segura de reducir el acoso y las posibles intimidaciones de tipo sexual. Era una forma de encajar en el ideal patriarcal de la posesión de las mujeres por sus parejas hombres a cambio de no ser hostigadas por nadie más. Como práctica habitual, los profesores acostumbraban consumir bebidas alcohólicas al interior del plantón. Con la excusa de las rondas de vigilancia nocturna pasaban la noche entera tomando, cantando, gritando, eran la representación del "macho mexicano" en su papel de cuidador y mantenedor del orden. Así pues, las mujeres nos encontrábamos atravesadas por dos opresiones: la del gobierno y la de los hombres al interior del magisterio.

Considero importante puntualizar que mi intención en este análisis no es romantizar la idea de sororidad o de las relaciones entre mujeres por el hecho de serlo, sino reconocer 
en ellas una complicidad, una formación de alianzas ante situaciones de riesgo, vulnerabilidad e incertidumbre. Parto pues de mi experiencia, recuerdos, evocaciones y de testimonios compartidos para posteriormente analizarlos a la luz de la teoría y metodología detallada en el Capítulo II.

\subsection{Los relatos}

\subsection{1 iNo importa lo que pase, no mires hacia atrás!}

¡No importa lo que pase, corre y no mires para atrás! Esa es la consigna que nos repetíamos constantemente durante las marchas; aunque ya tenía varias experiencias, aquella del 12 de septiembre de 2013 en el Aeropuerto Internacional de la Ciudad de México puso a prueba mi capacidad de reacción. Después de una semana durmiendo mal y poco, los rumores de una represión por parte de los granaderos sonaban por todos lados. La importancia del Aeropuerto que habíamos bloqueado horas antes hacía predecible un fuerte despliegue de seguridad por parte de la fuerza militar, el panorama para ese día pintaba mal. A pesar de ello, provistas de pañuelos, botellas de Coca-Cola y vinagre para contrarrestar los efectos del gas lacrimógeno en caso de ser agredidxs, mis compañeras y yo nos unimos al tumulto de maestrxs. Comenzamos a caminar. Como siempre, platicábamos mientras caminábamos, hacíamos bromas, planeábamos donde comeríamos, aunque en el fondo estaba la preocupación del enfrentamiento. Mi amiga Sonia, quien no acudió y se quedó en Oaxaca, me había mandado un par de mensajes al teléfono móvil, advirtiéndome del peligro. Para mí todo estaba bajo control, mientras no me separara del grupo. Continuamos caminando hasta que la marcha comenzó a detenerse: se corrió la voz de que habían rodeado la zona y debíamos intentar salir como se pudiera. En los altavoces se escuchaba la instrucción ;Que las mujeres se regresen al campamento, los hombres nos quedamos! Primero en calma, después de prisa caminamos en dirección contraria a nuestra llegada. Nunca había visto algo igual, efectivamente estábamos rodeadxs. Había helicópteros volando tan bajo que era imposible escucharnos. El viento que provocaban las hélices se sentía justo encima de nuestras cabezas. Granaderos con tanquetas y la policía federal habían acordonado la zona. Comenzó el enfrentamiento. Al ver eso me entró un sentimiento al cuerpo que nunca antes había tenido. Me estremecí de miedo. Los granaderos empezaron a arrojar agua fétida desde 
las tanquetas. Aquello se volvió una locura y todxs comenzamos a correr, estaba con la adrenalina a tope entre el miedo e impotencia por las acciones del gobierno. Recuerdo los olores a humo, goma quemada, el pestilente de las armas fétidas... el olor del miedo. Sin decir ni una palabra, Ana y yo nos tomamos de la mano y comenzamos a buscar una salida. Fue imposible no mirar atrás, ahí se quedaba mucha gente resistiendo, no sólo hombres, había infinidad de mujeres llevando piedras en las manos, en los rebozos, en cubos, algunas gritaban ¡Resistan compañeras, no se vayan! Yo no podía quedarme ¡a mí, a mí me venció el miedo!

Por la noche, ya de vuelta al campamento el recuento de los daños, las anécdotas de los que permanecieron y el miedo a revivir esa escena, me hicieron tomar la decisión de abandonarlo. Era el miedo a volverme a ver expuesta a una situación de tal violencia, era, en definitiva, el miedo a ser golpeada, gravemente herida o, en el peor de los casos, asesinada; miedo de no volver a casa. No hubo manera de convencer a Ana de regresar conmigo a Oaxaca, ella había resuelto permanecer hasta el último momento. Con lágrimas en los ojos, nos despedimos y emprendí la vuelta a casa. A la mañana siguiente el anuncio era oficial: el zócalo de la capital mexicana había sido desalojado. La Policía Federal Preventiva había hecho uso de las más duras formas de represión; en las calles había enseres ardiendo, casas de campaña destruidas y grupos de activistas golpeados, y replegados de manera forzada al Monumento a la Revolución.

\subsubsection{No nos van a cortar la dignidad}

Las conversaciones entre maestras son muy comunes, durante las marchas, los mítines o las noches de guardia. Las guardias nocturnas consisten en hacer recorridos de vigilancia en la entrada a los campamentos, son rotativas, duran dos horas y se caracterizan por prender fogatas. El significado comunitario de la fogata es muy íntimo: en las casas oaxaqueñas existe un espacio para el fuego, en donde se platica o se resuelven problemáticas a través del diálogo y el encuentro, intercambiando historias. Fue una de esas noches, que conocí uno de los relatos más estremecedores de agresión policiaca, es la historia de Aurora, una maestra que participó en el movimiento magisterial del $2006^{11}$. A continuación, rescato

\footnotetext{
${ }^{11}$ Movimiento magisterial-popular en Oaxaca, reprimido de forma brutal por el gobierno federal.
} 
su relato, que es a su vez mi recuerdo de sus palabras por la importancia que tuvieron para mí en ese momento:

"Los cohetes eran la señal de aviso, todo había empezado. Las mujeres comenzaban a agarrar piedras, a luchar, el olor del gas era insoportable, la $\mathrm{PFP}^{12}$ nos estaba ganando; de repente llegaron las tanquetas, cada quien caminó para su lado. Vi como los policías agarraron a una compañera, comenzaron a patearla, a golpearla, corrí a ayudarle, de repente me desvanecí. Cuando desperté estaba en un lugar frío y oscuro: era la cárcel. Solo estábamos mujeres. Fue una psicosis tremenda, nos amenazaron con matarnos, violarnos, subirnos al helicóptero ${ }^{13}$, desaparecernos... Era un miedo espantoso. Cuando nos sacaron de ahí, nos tomaron fotos, hicieron que levantáramos la cabeza, nos obligaron a decir nuestro nombre fuerte, fuerte. Yo me inventé uno. Después nos pidieron quitarnos la ropa, nos dejaron como Dios nos trajo al mundo. Hicimos trece sentadillas, nos gritaban de manera horrible, nosotras sólo podíamos contestar iSi señor! ¡No señor! Al día siguiente, como a las 10 de la mañana, nos empezaron a bajar para cortarnos el cabello. Yo soy mixteca ${ }^{14}$, para nosotras el cabello representa la dignidad de la mujer, lo más grandioso. El mío era hermoso y me gustaba mucho. Me puse a llorar. Una maestra se acercó y me dijo "Compañera, te cortaron el cabello, sé lo importante que es para ti, pero te voy a decir algo: jno te cortaron los ideales, jno te cortaron la dignidad! Esto me levantó el ánimo, me dio mucha tranquilidad. Nos quedamos sentadas una al lado de la otra, hasta que nos dejaron libres."

Escuchar la historia de Aurora fue la forma por la que comencé a empatizar con las mujeres activistas como mujeres. Inevitablemente, sus palabras influyeron en la creación de miedos por ser activista y mujer; es decir, tomé conciencia de que la represión policial tenía consecuencias diferenciadas según el género.

\footnotetext{
${ }^{12}$ Policía Federal Preventiva, forma parte del destacamento de las fuerzas armadas.

${ }^{13}$ El helicóptero era el medio de transporte a las cárceles de máxima seguridad del país. Una vez ingresando a esos penales las posibilidades de ser libres eran escasas.

${ }^{14}$ La Mixteca es una región del Estado de Oaxaca, como $\tilde{N} u$ Saavi: Lugar de las nubes. El gentilicio es a la vez una identidad étnica de quienes así se reconocen.
} 


\subsubsection{Los desafíos de lo cotidiano}

Comenzaba a amanecer, las casas de campaña, como siempre, estaban húmedas por tantas mañanas expuestas al rocío de la madrugada; la maestra Alma, mi mentora en la profesión y lucha magisterial, nuevamente padecía el suplicio de no encontrar aseos disponibles a las 6:00 de la mañana. La Ciudad de México tenía un gran problema matutino: falta de sanitarios públicos. Del monumento del Ángel de la Independencia a la residencia de los Pinos ${ }^{15}$ era la peor ruta. Al ser la primera una zona comercial y la segunda residencial, la misión de encontrar un sanitario/servicio se volvía imposible. En todas las asambleas estatales ${ }^{16}$ la petición de las maestras era la misma: habilitar aseos portátiles ¡Nunca fueron escuchadas! Así que, ahí estábamos otra vez deambulando por las calles en busca de sanitarios. Después del tercer embarazo, la maestra Alma había tenido un desprendimiento de vejiga que la hacía susceptible de infecciones y le impedía contener por mucho tiempo la orina. Era fácil sentir su desesperación. El final de la historia era el mismo: terminaba orinando detrás de algún auto o de un árbol con el miedo añadido de ser sorprendida por la policía y recibir una multa. Lo mismo ocurría cuando las marchas coincidían con la menstruación, el tabú del tema dificultaba encontrar apoyo en los compañeros. Siempre en grupos de mujeres, conocidas y desconocidas, sufríamos el martirio del cambio de compresa, el cuidado de no mancharnos, el préstamo de pastillas para el dolor y los consejos de remedios naturales. ¡Resistir, resistir! aunque los cólicos duplicaran el cansancio. Las rutinas diarias se volvían grandes logros. Por la noche, a la hora de dormir se escuchaba el bullicio en el campamento, los pases de lista, un toque de queda interno donde la instrucción de no salir sola no estaba escrita, pero se respetaba. El miedo a quien estaba afuera pero también dentro. A lo lejos se escuchaba la consigna ;Hasta la victoria siempre camaradas! La pregunta sigue siendo ¿Cuándo la victoria será para nosotras?

\footnotetext{
${ }^{15}$ En esta ruta, la zona centro de la capital estaba a 10 kilómetros de distancia aproximadamente.

${ }^{16}$ Reuniones semanales de los dirigentes y representantes de la Sección XXII para tomar decisiones y consultar las necesidades a las bases.
} 


\subsubsection{Nosotras somos mayoría}

La sombra del 2006 estaba presente, la experiencia vivida aquel año era una conversación constante en el campamento, se había considerado comenzar el levantamiento de las barricadas ${ }^{17}$. Las maestras de nivel preescolar eran famosas por su habilidad para organizarse. Al ser el nivel con total dominio de mujeres, -no había ni un solo maestro en ese nivel-, era muy interesante ver la distribución de tareas entre ellas. Se organizaban para preparar café y comida, pero también para montar las trincheras, juntaban palos, costales, tierra. Parecían hormigas a la hora de colectar provisiones. Eran muy creativas, usaban las compresas menstruales para reforzar los cubrebocas ${ }^{18}$ que utilizamos para protegernos de los gases lacrimógenos, así como para evitar rozaduras en los pies. El testimonio de Alicia, una compañera de preescolar, es un claro ejemplo de sororidad y resistencia entre mujeres. Por ello es tan importante para mí recobrar su relato, de la manera más fiel a su contenido:

"En mi centro de trabajo somos muchas y hacemos equipo; no te voy a decir que todas me caen bien, o que todas somos amigas, pero siempre estamos juntas y hemos aprendido a organizarnos. Aquí decimos "sin que te conozca te ayudo, sin que me conozcas me ayudas". Las de nuevo ingreso se emocionan mucho, llegan muy combativas, quieren entrarle a todo y da gusto verlas participando, luego se desilusionan de ver tanto hombre mandando, dando instrucciones, pero en nuestro nivel ¡no! A los que nos quieren mandar los ponemos quietecitos y terminan "alineándose”. Los compañeros son muy cabrones, están acostumbrados a que la esposa les haga todo, pero aquí se chingan, si quieren comer que ayuden en la cocina, si yo puedo agarrar piedras y lanzar cohetes, ellos pueden agarrar la cuchara y prender lumbre (hacer fuego para cocinar). Luego se quieren pasar de listos con nosotras, nos espían cuando nos cambiamos de ropa o cuando nos bañamos, ya hemos denunciado a varios en la asamblea y les advertimos que nosotras somos pacíficas, aguantamos hasta donde se pueda, pero que no abusen porque se les va a aparecer el diablo. También hemos peleado porque se respeten nuestros derechos, yo no tengo hijos, pero es muy triste ver a las compañeras con sus chamaquitos en los campamentos, luego andan corriendo con

\footnotetext{
${ }^{17}$ Consiste en la construcción de murallones hechos de varios objetos (palos, piedras, llantas, alambre de púas, costales, etcétera) cuya función es principalmente la autodefensa y protección de determinadas áreas de interés estratégico.

18 Mascarillas.
} 
ellos en las marchas. Ya propuse en la Estatal que se cree una guardería, que las compañeras con hijos pequeños no vengan, pero estos ni a las embarazadas respetan. A nosotras nos falta organizarnos, somos mayoría, siempre andamos en la lucha pero no nos consideran. Tenemos muchos asuntos pendientes".

Fue inspirador para mí escucharla, saber que las mujeres organizadas tenían grandes resultados, que podían no solo hacerlo, pero hacerlo de maravilla. Fue otro ejemplo para mi de que unidas nos empoderamos. Definitivamente juntas somos más fuertes.

\subsection{Análisis}

En este apartado, mi intención es hacer el análisis de los relatos recuperados a través de mis rememoraciones y narrados anteriormente, a fin de identificar desde una perspectiva feminista, las relaciones de sororidad que se tejen entre las mujeres militantes de la sección XXII de la Coordinadora Nacional de Trabajadores de la Educación en Oaxaca, que forma parte del Sindicato (CNTE). Así, para el análisis he identificado aquellas características comunes de los relatos, clasificándolas en las tres dimensiones descritas en el marco teórico a partir de la teoría que propone Marcela Lagarde: la dimensión ética, la política y la práctica como expliqué previamente en el Capítulo 2 correspondiente al marco metodológicoconceptual.

\subsubsection{Dimensión ética}

Identifico dimensiones éticas como la intención de apoyo mutuo y de cuidados que nos procuramos entre maestras; además del autocuidado. Nos ayudábamos tanto para cubrir necesidades corporales como emocionales, de manera temporal o duradera. Éstas reflejan alianzas feministas que, aunque en el momento en el que sucedieron no las nombrábamos, las reivindico como tales ahora. Como expresa la antropóloga mexicana Marcela Lagarde "necesitamos legitimar, autorizar y hacer universalmente necesaria la cultura feminista al mostrarla como fuente indispensable de la cultura del desarrollo y la convivencia democrática basada en la igualdad y la libertad humanas" (Lagarde 2006, pág. 60). 


\section{Formando redes, tejiendo la solidaridad}

Siguiendo las palabras de Marcela Lagarde "la sororidad es un pacto político entre pares. Los pactos entre nosotras son limitados en el tiempo y tienen objetivos claros y concisos, con ellos las mujeres ampliamos nuestras coincidencias y potenciamos nuestra fuerza para vindicar nuestros deseos en el mundo" (2012, pág. 4). Desde mi perspectiva, estos pactos (tanto tácitos como expresos) forman redes de ayuda. De las narraciones puede identificarse la formación de grupos y la seguridad que me daba adherirme a uno. Es notorio también en la empatía que las maestras nos mostramos en las necesidades comunes como la menstruación, el cuidado de las casas de campaña, compartir pastillas, la lucha cuerpo a cuerpo cuando se procura que nadie se quede sola por las noches o a nivel emocional cuando compartimos miedos, incertidumbre, o nos transmitimos tranquilidad y confianza. Un ejemplo de esto puede verse en la ayuda que Aurora ofreció a la compañera golpeada cuando corrió a auxiliarla incluso cuando también ella se encontraba en una situación de vulnerabilidad. En muchas ocasiones estas redes no se tejen por afinidad sino por solidaridad, tal como manifiesta Alicia cuando se refiere a las maestras y sentencia que no todas son amigas pero se rigen por el principio "sin que te conozca te ayudo, sin que me conozcas me ayudas". Se crean redes como las que se tejen en las hamacas. El yo dentro de un nosotras como expresión del tejido comunitario, lo que propicia llegar por consenso a la toma de decisiones y contribuir a la construcción de espacios habitables para todas.

\section{Creando alianzas}

Crear vínculos con otras enriquece la experiencia de los procesos que se viven cotidianamente en las manifestaciones. Se crean alianzas temporales, compartiendo espacios de unión con un objetivo o meta en común. Estas conexiones momentáneas pueden ser consideradas como movimientos tácticos para mantenernos a salvo, aprovechando el espacio junto con las compañeras que nos rodean. Se producen así relaciones de reciprocidad de las que las maestras nos beneficiamos y en las que la ayuda se presta mientras dicho vínculo dure. En el relato de Aurora, esta alianza se refleja en el encuentro fortuito con otra compañera que la anima ante la pérdida de su cabellera. Sin conocerse se mantienen unidas

durante la espera para su liberación. No se conocen, pero ya no están solas. Otra alianza fue 
la establecida con Ana y quedó manifiesta cuando nos tomamos de la mano y corrimos para buscar la salida durante el desalojo del aeropuerto.

\section{Autocuidado}

Considero importante mencionar que, si bien es cierto, establecemos alianzas y procuramos el cuidado de la otra, es importante el autocuidado. Para mí fue difícil aceptar la decisión tomada por Ana de quedarse en el campamento, incluso sentí culpa por abandonarla, pero le di prioridad a mi seguridad. Ha sido complejo aprender a respetar las decisiones de los demás y conocer mis propios límites. Sólo en estos relatos, describo tres episodios que considero fueron estrategias de autocuidado: el enfrentamiento en el Aeropuerto en el que decido abandonar, el repliegue ante el desalojo cuando decido irme a casa y, por último, declinar pertenecer a la organización por el alto riesgo. Soy activista y creo firmemente en la causa, por lo que tengo constantes sentimientos de culpa o traición cuando abandono las actividades. Sin embargo, y como he detallado en el capítulo II, reconozco el peligro que implican estas movilizaciones. Hay que resaltar además que existe una política instaurada de miedo a la policía y a las prácticas del Estado, lo que me impide permanecer. El bon sens que se activa ante las situaciones extremas y que me hace pensar en las consecuencias, el temor a ser desaparecida o la sensación de alerta que hasta ahora me invade cuando escucho helicópteros o la sirena de las patrullas. Admiro el valor de las compañeras que están dispuestas a dar su vida por el movimiento, pero no puedo igualarlo.

\subsubsection{Dimensión política}

En cuanto a la dimensión política, he identificado en los relatos las aspiraciones de liberación de las compañeras tanto de las prácticas de opresión que encabeza el Estado, a través de las fuerzas de seguridad, como de las ejercidas dentro del mismo sindicato por los compañeros. Doy también cuenta de la construcción del poder político que el acompañamiento entre las militantes facilita y de la importancia de generar una genealogía de las mismas, que presento a continuación. 


\section{Estamos juntas, estamos seguras}

En el nivel político figuran acciones de acompañamiento, esto significa estar al pendiente de las demás, buscar la unión para sentirnos seguras. En situaciones comunes como la búsqueda de sanitarios con la maestra Alma; o de protección en el caso de los grupos que se forman durante los desalojos. Considero que lo anterior se relaciona con las políticas del cuidado feminista, en donde se pugna por acompañar a la otra, comprendiendo sus necesidades y generando una relación de igualdad. Se trata pues de crear comunidad, de cuidar de la otra mientras se confía que la otra también está cuidando de nosotras. Este acompañamiento se identifica en el relato "Los desafíos de lo cotidiano" donde la totalidad de las actividades se hacen en compañía, compartiendo estrategias, utensilios o medicina. Para mí es interesante observar cómo la mayoría de las veces estas acciones se hacen de forma automática, surgen de una preocupación genuina por el bienestar de las demás.

\section{Preexistir. Recuperando las experiencias}

Conocer y recordar las experiencias de otras mujeres me ha permitido potencializar las tácticas de resistencia. Desde mi ingreso al magisterio, conocí a través de anécdotas la manera en que debía reaccionar en caso de agresiones policiacas. La Coca-Cola y el vinagre tomaron un significado reparador, aprendí a mantenerme en el anonimato por temor a los infiltrados. Ingresé a la Coordinadora en el año 2009, la reciente represión sufrida en 2006 todavía tensaba el ambiente. Siempre me pareció interesante ver como las maestras compartían su experiencia cuando estábamos solas, ya que si lo hacían en presencia de los compañeros generalmente eran interrumpidas. Para mí sus historias eran sorprendentes, algunas de ellas estaban dispuestas a dar la vida por el movimiento, muchas fungieron como voceras en los medios de comunicación durante la toma de la radio y la televisora local, pero al interior de la Coordinadora ya no figuraban, habían quedado excluidas.

Sin lugar a dudas las conversaciones nocturnas alrededor de las fogatas fueron inspiradoras para redactar este TFM, las evocaciones del desalojo por la Policía Federal Preventiva, el recuento de lxs muertxs, desaparecidxs y la resistencia de las mujeres son historias que merecen ser contadas. Poner nombre a lo que sucede supone reflexionar sobre ello, darse cuenta de que existe. Y contarlo se vuelve casi una obligación. 


\section{Genealogía de las mujeres}

Compartir experiencias es parte de las tácticas para romper con la brecha generacional y convertirla en un puente para relacionarse con personas de distintas edades, revalorando los marcos como valiosos, convirtiendo nuestros espacios de lucha en espacios bidireccionales de aprendizaje, tendiendo puentes desde el conocimiento adquirido en cada generación. Es urgente y fundamental recuperar lo que han hecho nuestras predecesoras, conocer los descubrimientos que han realizado, las luchas que han vencido. Así, lo anterior, como explica Blanco, “...permite a las mujeres tener genealogía, saber que tenemos raíces, vincularnos a otras que han estado antes que nosotras, reconociendo que han pensado, han creado, han sido libres..." (Blanco, 2015: 18).

\subsubsection{Dimensión práctica}

La parte práctica se presenta como "un hacer", un conjunto de acciones específicas que contribuyen a la creación de alianzas y al empoderamiento de las mujeres participantes. Las acciones que las maestras ejecutamos en las tres formas de protesta aquí narradas como marchas, plantones y bloqueos, tienen la intención de demandar justicia para nuestrxs estudiantxs y para nosotras. Tenemos también el firme propósito de hacer presencia, impactar en lo público y en la lucha magisterial; presencia en las calles, gritando consignas, resistiendo el frío, aguantando el hambre. En los relatos existen varios ejemplos prácticos: la construcción de barricadas de las maestras de preescolar, el papel de las compañeras que transportaron piedras en los rebozos y las cubetas. El hecho mismo de dormir en el piso, comer en la calle, preparar café y comida, pero también lanzar cohetes y hacer rondas de vigilancia. Aprender de las maestras de preescolar y la forma en que se imponen a los compañeros, el proceso mismo de reconocerte como sujeta con agencia, capaz de denunciar en las Asambleas Estatales. Es decir, tener la capacidad de alzar la voz y demandar justicia: en la calle en contra del mal gobierno y en las asambleas denunciando el abuso de los compañeros. 


\section{Conclusiones, tejiendo redes de empoderamiento en la Sección XXII de la CNTE}

¿Qué habría sido de las mujeres en el patriarcado sin el entramado de mujeres alrededor, a un lado, atrás de una, adelante, guiando el camino, aguantando juntas?

No habríamos sobrevivido a los avatares de la vida sin otras mujeres conocidas y desconocidas, próximas o distantes en el tiempo y en la tierra

(Lagarde, 2006).

Los procesos de reflexión colectivos entre mujeres son un aporte importante que posibilita tomar dimensión de la magnitud del problema de la violencia de género. El feminismo como corriente crítica ha instado, a lo largo de su historia, a la creación de procesos colectivos y empáticos entre mujeres que permitieran problematizar sobre los atravesamientos patriarcales y las experiencias vitales de las mujeres. En este sentido, el ejercicio de reflexividad impulsado por mujeres tiende a quebrantar uno de los mayores recursos del patriarcado de sobrevivencia, mantener a las mujeres aisladas, divididas y enemistadas. Por lo cual, la mayor trasgresión política de las mujeres es su alianza, su coalición, la sororidad (Lagarde, 1996).

A través de una metodología autoetnográfica, la cual me ha permitido construir un diálogo con las experiencias vividas como activista y en relación con las narraciones de mis compañeras militantes, he buscado visibilizar en esta investigación las relaciones sororales de las maestras que participamos en las movilizaciones del sector magisterial pertenecientes a la CNTE en Oaxaca que conducen al empoderamiento a fin de sobrevivir a las manifestaciones sindicales desde el ser mujer.

En este sentido, he estructurado esta investigación en tres capítulos principales. En una primera instancia, he visto necesario delimitar el terreno y el contexto histórico para poder situar a quienes me lean en la lucha histórica del CNTE en Oaxaca, explicando las demandas y dificultades de nuestras movilizaciones. En la segunda parte de este trabajo, he abordado los marcos metodológicos y conceptual, explicando el proceso y métodos que utilizo para hacer la narración de la autoetnografía. Por otra parte, he teorizado sobre los conceptos claves abordados con la intención de darles un sustento teórico. Finalmente, en el 
tercer capítulo entré a las hitos vitales, como define Teresa del Valle (2017), enfocándome en las formas que tienen las mujeres de construir las relaciones sororales.

Es así que he identificado que las relaciones sororales se convierten en una forma de empoderamiento para las maestras de la Coordinadora, en el sentido en que en dichas relaciones se encuentra la posibilidad de obtener el poder, señalar opresiones, denunciar abusos y marcar precedentes de participación política para futuras generaciones. Esto no quiere decir que todas las mujeres son amigas entre sí, ni que se quieren, pero sí que son compañeras y que están unidas en una misma lucha, bajo un mismo objetivo y manteniendo una relación de compañerismo que implica cuidados, coordinación, respeto, que yo identifico como sororidad. He concluido también que el estar unidas y apoyarse mutuamente a través de las estrategias descritas en el capítulo 3, las mujeres se empoderan mutuamente y a sí mismas. Las palabras de ánimo en momento críticos o de extrema vulnerabilidad, la confianza mutua, el compartir víveres y medicamentos, el cuidado mutuo en diferentes aspectos, son técnicas imprescindibles que hacen nuestras luchas más llevaderas y seguras. Del mismo modo, he identificado también que existe, en esta línea, una enorme diferencia de estas prácticas que he reconocido tal vez no única, pero casi exclusivas entre las mujeres, con las de los hombres, quienes no reconocen los mismos riesgos y por lo tanto no muestran señales de protegerse y cuidarse entre ellos. Por otra parte, las necesidades biológicas, como la menstruación y los embarazos, generan también lazos de complicidad entre las mujeres durante las movilizaciones.

Respecto a las tres categorías recogidas de la propuesta de Marcela Lagarde (2012) en relación a las dimensiones éticas, políticas y prácticas de la sororidad con la construcción del empoderamiento se encuentran en las acciones expresadas en los relatos, en la posibilidad de las mujeres de tomar la palabra, el uso de la voz en asambleas estatales y, tomar conciencia del protagonismo de nuestras acciones. Además de verse reflejadas en la consecución de derechos laborales como aumento salarial, el respeto a la antigüedad y en los triunfos obtenidos gracias a las movilizaciones, algunos de ellos son la distribución gratuita de útiles escolares desde el año 2012, la creación de comedores escolares, y lo más importante construirnos como referente de lucha para la niñez oaxaqueña, bajo la consigna ;Lxs maestrxs luchando, también están enseñando! Considero necesario puntualizar que la opinión de la 
sociedad está polarizada en esta lucha, mientras una parte nos respalda otra nos critica los medios de comunicación cooptados por el Estado han contribuido en desvirtuar la lucha.

El empoderamiento en cuanto capacidad de acción, es una práctica feminista que tiene que ver con la posibilidad de las mujeres de tomar la palabra e incidir en la acción política colectiva a través de constituir redes entre sí. Como modo de construir poder a través de los pactos o alianzas críticas, el empoderamiento es una práctica que pretende contrarrestar la dispersión y confinación atomizada en los espacios privados, causa histórica de la debilidad política de las mujeres dentro de la estructura patriarcal (Azcuy, 2012, pág. 20). Así pues, es una necesidad urgente echar mano de estrategias colectivas que desde nuestros propios espacios contribuyan a visibilizarnos, a encontrar espacios juntas donde podamos ser escuchadas, a generar alianzas con las otras, para sobrevivir a un sistema que no fue diseñado para mujeres, pero dentro del cual hemos llegado a ser mayoría y en el que estamos luchando por ser reconocidas. Hasta ahora hemos tejido alianzas, estamos construyendo espacios y generando condiciones para que las que vengan detrás de mi: hermanas, sobrinas, amigas, alumnas, sepan que existen opciones y lugares a los que ya podrán acceder.

Si bien es cierto en el GEMMA he aprendido a conciliar la teoría y la práctica, no puedo concluir esta Tesis Final de Master sin un producto, del análisis de las experiencias vividas surge el Decálogo de Sororidad anexo como contribución a la visibilización de las prácticas sororales en la Sección XXII.

Para concluir; tengo la lucha clara, identificado al enemigo y la forma de incomodarlo pero no soy la única; en la Sección XXII de la Coordinadora Nacional de Trabajadores de la Educación existimos mujeres luchando por el bienestar de nuestrxs alumnxs y el propio, mujeres orgullosas de nuestras pieles que son del color de la tierra, mujeres que honramos la justicia, la libertad y el lema ;Para todas, todo! Porque ¡todas somos compañeras! 


\section{DECÁLOGO DE SORORIDAD}

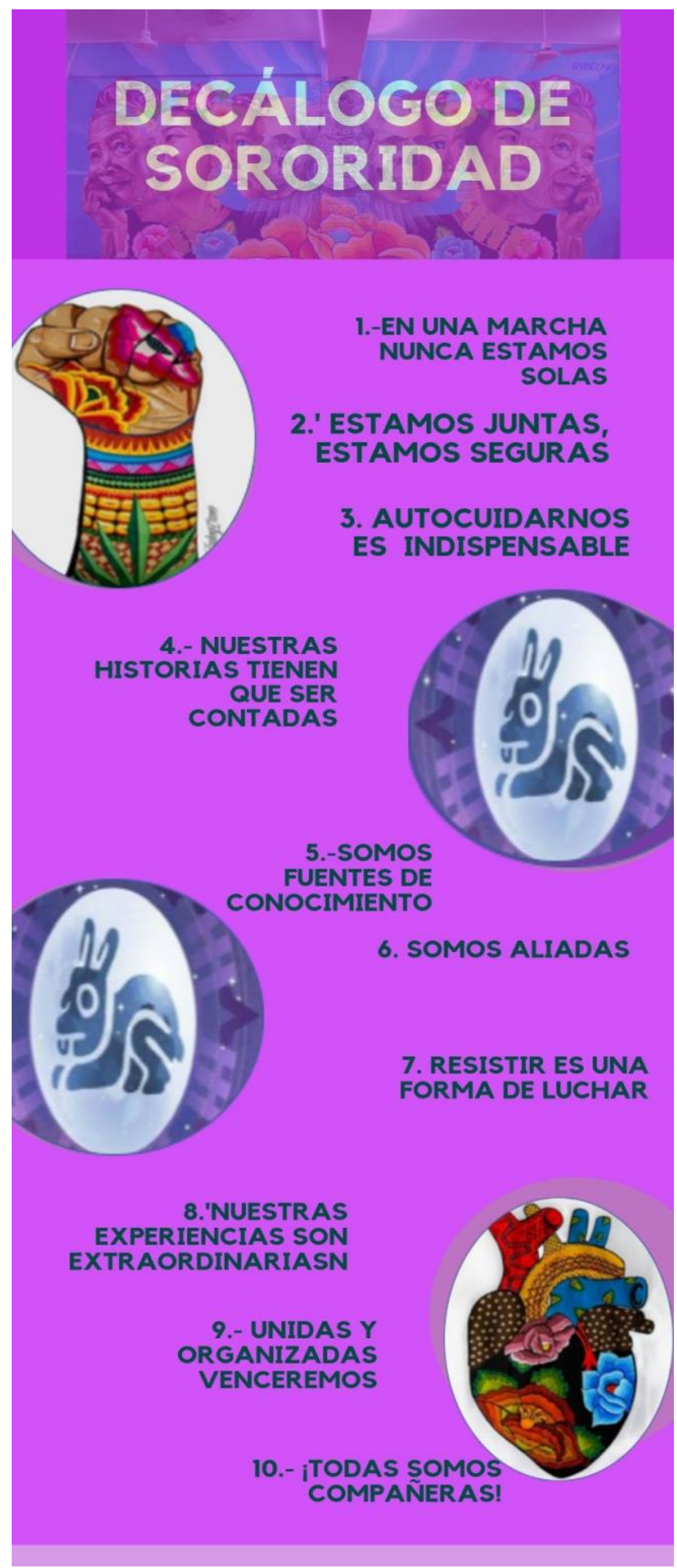




\section{Bibliografía}

Aldecoa, Josefina. 2005. Historia de una maestra. Barcelona: Anagrama.

Ahmed, Sara. 2014. The Cultural Politics of Emotion. Edimurhg: University Press Ltd.

Amorós, Celia. 1994. «Espacio público, espacio privado y definiciones ideológicasde 'lomasculino'y 'lo femenino'.» En Feminismo, igualdad y diferencia, de Celia Amorós. México: UNAM-PUEG.

Barraza, Eduardo. 2010. «Oaxaca en llamas: Memoria de un conflicto.» Barriozona Revista Comunitaria 28-37.

Bensusán, Graciela. 2011. «El SNTE: una experiencia singular en el sindicalismo mexicano.» El cotidiano (168): 17-32.

Blanco, Nieves. 2012. Educar en femenino y en masculino. Madrid: Universidad Internacional de Andalucía, Akal.

Brooks, Abigail, y Sharlene Nagy Hesse-Biber. 2007. «An invitation to feminist research.» En Feminist research practice, de Sharlene Nagy Hesse-Biber, y Ptricia Lina Leavy, 1-26. California: Sage Publications.

Butler, Judith. [1993] (2011). «Performative acts and gender constitution. An essay in phenomenology and feminist theory.» En The art of art history, de Donald Preziosi, 356-366. New York: Oxford University Press.

Butler, Judith. [1993] 2011. Bodies that matter: on the discursive limits of «sex». New York: Routledge.

Campos, Alicia. 2012. Hacia una nueva costriccpion del feminsmo. México: Fondo de Cultura Económica.

Castillo Cisneros, María del Carmen. 2006. Comisión Nacional para el Desarrollo de los Pueblos Indígenas. Tacuates. México.

Cencos. 2019. Centro de Comunicación Social de la Sección XXII. Oaxaca, 18 de junio. https://www.cencos22oaxaca.org/category/documentos-varios/.

Collectiu investigacció. 2005. Recerca Activista í Moviments Socials. El viejo topo. Barcelona.

Comins, Irene Mingol. 2007. «La ética del cuidado: contribuciones a una transformación pacífica de los conflictos.» Feminismo/s 9 93-105. 
CONEVAL. 2019. «Consejo Nacinal de Evaluación de la Política de Desarrollo Social.» Cd. de México. Último acceso: 8 de junio de 2019. https://coeval.org.mx.

Del Valle, Teresa. 2017. «Metodología para acceder al estudio de la ciudad: desde la evocación, la preexistencia y el pasado». En Cartografías de género en las ciudades antiguas, editado por Cándida Martínez López y Purificación Ubric Rabaneda, 29-46. Colección Feminae 30. Granada: Universidad de Granada.

Eltit, Daniela. 2016. «Camila Vallejo: una misión cumplida.» Debate feminista (CIEG UNAM) 51: 189-198. Último acceso: 22 de febrero de 2019. http://www.debatefeminista.cieg.unam.mx/wpcontent/uploads/2016/03/articulos/046_19.pdf.

Evans, Elizabeth. 2015. The politics of third wave feminisms: Neoliberalism, intersectionality and the State in Britain and the US. London: Palgrave Macmillan .

Fernández, Olaya. 2010. «Mecanismos de exclusión femenina.» En Miradas interdisciplinares para un mundo en igualdad, de María Josefina \& Goicoechea Gaoma Sebastián Calvo, 45-60. Logroño: Univresidad de la Rioja.

Foucault, Michel. 1988. «El sujeto y el poder» Revista mexicana de sociología 50 (3): 3-20. Foucault, Michel. 1976/2006. «Historia de la sexualidad.» La voluntad de saber (Siglo XXI) I.

Harding, Sandra. 2002. «¿Existe un método feminista?» En Debates en torno a una metodología feminista, traducido por Gloria Bernal, 9-34. México: UAM, Unidad Xochimilco, División de Ciencias Sociales y Humanidades: UNAM, Programa Universitario de Estudios de Género.

Hernández, Ana Aguirre Callejas \& Ruth Sainz. 2016. «Feminicidios deben reconocerse como vidas perdidas.» La de Puebla. http://www.poblanerias.com/2014/10/feminicidios-deben-reconocersecomo-.

INEGI. 2015. «Instituto Nacional de Estadística y Geografía.» México. https://www.inegi.org.mx/.

Lagarde, Marcela. 1997. «Claves feministas para el poderío y la autonomía de las mujeres.» Managua: Puntos de encuentro, 5,6,7 de Mayo.

Lagarde, Marcela. 2012. «Pacto entre mujeres. Sororidad.» El feminismo. Hitos, claves y topías 557-569. 
León, Magdalena. 2001. «El empoderamiento de las mujeres: Encuentro del primer y tercer mundos en los estudios de género.» La ventana 94-106.

León, Samuel. 2005. «La situación laboral en América Latina.» Revista Mexicana de Sociología 40 (2): 29-62.

Leyva, Jessica. 2010. «Las alternativas de resistencia del movimiento magisterial oaxaqueño.» Oaxaca: UNAM, Octubre.

Lugo, Guadalupe. 2015. «Defensa del derecho de reunión y la garantía de vivir juntos.» Defensa del derecho de reunión y la garantía de vivir juntos. México: Gaceta de la UNAM. 8-19. Último acceso: 22 de mayo de 2019. http://www.gaceta.unam.mx/20150413/conferencia-magistral-de-judith-butler-enla-unam/.

Martínez, Jaime. 2009. Sindicalismo y represión en Oaxaca. Cd. de México: Instituto Mora.

Mohanty, Chandra. 2008. «De vuelta a "Bajo los ojos de Occidente": la solidaridad feminista a través de las luchas anticapitalistas». En Descolonizando el feminismo: teorías y prácticas desde los márgenes, editado por Liliana Suárez-Navaz y Rosalva Aída Hernández Castillo, 1. ed, 407-64. Feminismos. Madrid: Cátedra.

Núñez, Silvia. 1990. Maestras oaxaqueñas: Movimiento magisterial, vida cotidina y democracia. México: Universidad Nacional Autónoma de México.

Navarro, Luis Hernández. 2016. «La larga marcha de la CNTE.» El cotidiano 20-31. http://redalyc.org/articulo.oa?id=32548630003> .

Paredes, Julieta. 2010. Hilando fino desde el feminismo comunitario. La Paz, Bolivia: Colectivo El rebozo.

Pérez, Jorge. 2015. «Marcha de las cacerolas; la reivindicación de las oaxaqueñas.»La Jornada, 2 de agosto. Último acceso: 8 de junio de 2019. https://www.jornada.com.mx/2015/08/02/politica/011n2pol.

Pipitone, Ugo. 2011. Modernidad congelada. Un estudio de Oaxaca, Kerala y Sicilia. México D.F: CIDE.

Posadas, Luisa. 2008. $\quad$ «Pactos mujeres» www.creatividadfeminista.org/articulos/pactos $2 . \mathrm{htm}$.

Ramírez, Carlos. 2016. «Las revueltas de Oaxaca». Letras Libres. 15 de septiembre de 2016. http://www.letraslibres.com/mexico/politica/las-revueltas-oaxaca. 
Rich, Adrienne. 1987. «Notes Towards a Politics of Location.» En Blood, Bread and Poetry, de Adrienne Rich, 210-232. London: Virago.

Riba, Lucía. 2016. «Memoriales de mujeres: la sororidad como experiencia de empoderamiento para resistir a la violencia patriarcal.» Franciscanum LVIII (165): 225-262.

Toledano, José. 2003. El sindicalismo en México: Historia, crisis y perspectivas. México: Fondo de Cultura Económica. 